Article

\title{
Knowledge Management Infrastructure Framework for Enhancing Knowledge-Intensive Business Processes
}

\author{
Itzhak Aviv ${ }^{1,2, *(\mathbb{D})}$, Irit Hadar ${ }^{2}$ and Meira Levy ${ }^{2,3}$ \\ 1 School of Information Systems, The Academic College of Tel Aviv-Yaffo, Tel-Aviv 6676151, Israel \\ 2 Department of Information Systems, University of Haifa, Haifa 3498838, Israel; hadari@is.haifa.ac.il (I.H.); \\ lmeira@shenkar.ac.il (M.L.) \\ 3 School of Industrial Engineering and Management, Shenkar College of Engineering, Design and Art, \\ Ramat Gan 5252626, Israel \\ * Correspondence: itzhakav@mta.ac.il; Tel.: +972-529-282-757
}

check for updates

Citation: Aviv, I.; Hadar, I.; Levy, M. Knowledge Management Infrastructure Framework for Enhancing Knowledge-Intensive Business Processes. Sustainability 2021, 13, 11387. https://doi.org/ $10.3390 /$ su132011387

Academic Editor: Nicholas Chileshe

Received: 31 August 2021

Accepted: 6 October 2021

Published: 15 October 2021

Publisher's Note: MDPI stays neutral with regard to jurisdictional claims in published maps and institutional affiliations.

Copyright: (C) 2021 by the authors. Licensee MDPI, Basel, Switzerland. This article is an open access article distributed under the terms and conditions of the Creative Commons Attribution (CC BY) license (https:/ / creativecommons.org/licenses/by/ $4.0 /)$.

\begin{abstract}
In this age of digital transformation, knowledge-intensive organizations strive to improve business outcomes and sustainability by improving their knowledge-intensive business processes (KIBPs) to obtain a competitive advantage. Many researchers have claimed that KIBP enhancement is possible through knowledge management (KM) initiatives supported by an effective KM infrastructure. Current KM infrastructures deal with formal KM procedures, where knowledge is created, stored, assimilated, and disseminated. Such activities, however, are designed to be performed outside of the business process. KM infrastructures are expected to be more effective when they include specific real-time knowledge procedures integrated into the operational flow of KIBPs. This paper explores how modern KM infrastructures can support KIBPs, considering both formal and operational KM procedures. Our study's essential contribution is the conceptual KM infrastructure framework (KMIF) developed based on grounded theory research. This infrastructure provides a systematic and robust approach, starting from the ground up, for structuring organizational knowledge assets across a range of KIBP environments. We define operational knowledge procedures directly involved in KIBPs, adding a layer to KM infrastructures beyond the formal knowledge procedures. A mixed-method case study was conducted to demonstrate and evaluate the proposed KMIF for enhancing business outcomes and sustainability of knowledge-intensive organizations.
\end{abstract}

Keywords: knowledge management infrastructure; knowledge processes; knowledge-intensive business processes

\section{Introduction}

Companies are looking for innovative strategies to compete in an era of globalization, new technologies, and increased market openness to improve their business processes and achieve long-term, sustainable customer relationships. Over the last few years, the application of knowledge management (KM) in the context of sustainability has become increasingly essential. Despite its relevance, this topic is still under-explored, offering several research opportunities [1]. KM strategies, such as knowledge storage and usage [2], knowledge sharing [3], and KM initiatives [4], have a substantial positive impact on the long-term viability of businesses. Knowledge storage is significant for knowledge utilization and, as a result, for organizational sustainability [3]. KM provides a significant boost in the pursuit of more sustainable operations in businesses [4].

The number of sustainable practices developed by organizations in response to new problems and stakeholder pressures is referred to as sustainability. From company strategy to business processes, these practices can be used across the board [5]. Organizations that incorporate sustainability into their business models and generate a competitive advantage will fare better than those that do not [6]. Operational excellence, which focuses 
on improving organizational and operational processes and increasing efficiency, is under sustainable development, reducing loss and making for better resource utilization, including knowledge, equipment, and materials [7]. Business process management, in which operations are coordinated and performed to generate value and meet strategic interests, is being reorganized to successfully promote sustainability [8]. When adequately executed, business processes can help organizations achieve good sustainability results across organizational boundaries [9].

Implementing business process improvement initiatives for enhancing business outcomes and sustainability is particularly challenging due to cross-organizational business processes in diverse geographic locations and cultures that depend on diverse and distributed knowledge [10]. KM has been identified as a crucial component of knowledgeintensive sectors characterized by technological complexity and a competitive environment [11]. The analysis of knowledge-intensive businesses is a relatively new literary phenomenon, dating back to the advent of the knowledge-based view of the organization [12]. The convergence of business process management and KM concepts in modern businesses is a challenging phenomenon to investigate and address. Despite the increasing interest among academics and practitioners, only a few publications specialize in this area [13].

Several papers published in recent years have highlighted that $\mathrm{KM}$ is acquiring a pivotal role in the global economy and is crucial for the competitiveness of both large organizations and small and medium organizations [11,14]. There is a growing emphasis on KM as a critical component of organizational strategy in knowledge-intensive organizations and as a significant catalyst for redesigning and reengineering knowledge-intensive business processes (KIBPs) $[10,13,15]$. The underlying principle is simple: knowledgeintensive organizations must use their knowledge assets efficiently to compete in today's dynamic high-tech market.

Indeed, effective KM improves the capacity of knowledge-intensive organizations, such as those in the software industry, to learn and adapt quickly and to react quickly to changes in technology, market conditions, and consumer preferences [16]. It seems that an effective KM infrastructure, established in the presence of organizational strategic goals and implemented to meet specific KIBP needs, can promote the achievement of strategic objectives by means of improved KIBP execution and outcomes. Our literature study on existing KM frameworks revealed that scientific data on the phenomena, its variables, and its determinants in the context of KM infrastructures in the knowledge industry, especially KIBPs, are limited.

Our concern regards the traditional KM infrastructure frameworks that do not target operational KIBP needs. Each KIBP is executed within a heterogeneous environment, including stakeholders involved in its execution, related knowledge sources, knowledge inputs and outputs, supporting operational technologies, etc. Therefore, using the existing KM infrastructure frameworks in the context of KIBPs may be insufficient since operational KIBP needs are highly complicated and require multiple views to examine their whole complexity, including technological, cultural, and KM procedures. Business process improvement approaches do not help meet this challenge either, as they do not explicitly deal with KM concerns within the business process environment $[17,18]$. We believe that focusing on a specific KIBP and incorporating KM procedures within this process can make a comprehensive KM infrastructure for knowledge-intensive organizations more effective and beneficial.

Thus far, limited empirical evidence has been reported on trends, phenomena, and contributing factors related to KM infrastructures of the knowledge-based industries, especially in the domain of KIBPs. KIBP management has a favorable impact on KM procedures. The duties of defining, obtaining, delivering, and recording knowledge are not mutually exclusive; rather, they should be implemented within processes [13]. The distinct context of knowledge-intensive organizations has not yet been extensively explored from an operations management viewpoint, leaving a gap in the literature on how to aid the 
resilience, flexibility, and innovation in such organizations. More particularly, there is a research gap affecting how the broader distinguishing qualities of knowledge-intensive organizations are manifested and sustained at a KIBP level [12]. There is a need for more extensive empirical evidence on KM infrastructures in the context of KIBPs to achieve a deeper and more practical understanding of the $\mathrm{KM}$ infrastructure components. The objective of this research was to define the required KM infrastructure components in the context of KIBPs. We advanced the theoretical and practical claims that KM infrastructure can play a significant but understudied role in assisting knowledge-intensive organizations in the implementation and monitoring of long-term sustainable KIBPs. The research question explored in this study was: What is the role of knowledge management infrastructure in business organizations that are based on KIBPs? Following it, we aimed to develop a comprehensive KM infrastructure framework (KMIF) that facilitates tacit knowledge capturing and manages actionable explicit knowledge in the context of KIBPs, aiming for the sustainable and operational enhancement of KIBP execution. The KMIF was built based on a mixed-method case-study research approach. We first defined KMIF properties utilizing qualitative research based on the grounded theory approach. Next, we applied quantitative research based on a structured survey. Starting from the ground up, this infrastructure provides a systematic and comprehensive approach for structuring organizational knowledge assets across a variety of KIBP contexts. We defined operational knowledge procedures that are directly involved in KIBPs, extending KM infrastructures beyond formal knowledge procedures.

The rest of the paper is structured as follows: Section 2 briefly reviews the literature on the characteristics of knowledge-intensive organizations and existing research on KM infrastructure. The research approach is described in Section 3, and the findings are presented in Section 4. Section 5 discusses the research findings, and Section 6 concludes the research.

\section{Literature Review}

In recent years, the focus on both $\mathrm{KM}$ and its role within organizations has increased. The role of knowledge exhibits dichotomous definitions such as explicit vs. tacit or organizational vs. personal knowledge. It is the source of many challenges to the standard epistemological concept of knowledge [19]. Explicit knowledge is structured knowledge that is simple to explain, document, save, and transmit digitally [20]. Instructions, protocols, practices, standards, licenses, publications, and technical paper reports are examples of explicit knowledge. Tacit knowledge is defined as "know-how" that exists purely in persons' minds and is not documented in any meaningful manner [19]. Because of its distinct distinction from the "know-what" aspect of explicit knowledge, which is more strongly associated with information and data, the question of where tacit knowledge has its roots is remarkably simple in determining how to create it within the rapid evolution of an organization. Data are a collection of symbols: disorganized, unannotated, fragmented, and unrelated to their utilization in various settings. Data lose their informational fervor and become meaningless unless they are given a meaning. They change to information when organized, evaluated, processed, and given meaning to make it relevant and usable [21]. It is a lot more challenging to define knowledge: it is defined, for example, as a "mix of fluid experiences, values, contextual information and intuition that provides a structure to evaluate and incorporate raw experiences and information" [22].

Theoretical and empirical research works were performed on different aspects of $\mathrm{KM}$, such as IT, organizational processes, and organizational cultures that support KM. Organizations tend to concentrate more on knowledge because they consider it essential for their survival [23]. They are intensely devoted to business process improvement initiatives, as they encompass the primary operational resources in knowledge-intensive organizations. To remain competitive, intellectual and operational resources must be adequately managed. The following subsections provide the theoretical background for understanding the main concepts of knowledge-intensive organizations, KM, and its infrastructure. 


\subsection{Knowledge Management}

$\mathrm{KM}$ is defined as "the systemic and organizational process of acquiring, organizing, and communicating knowledge for employees who may use it in order be more effective and productive" [24]. Knowledge dissemination developed from the necessity of organizations to make better and more efficient use of their knowledge. KM can help gain a competitive edge and save time in developing knowledge-intensive businesses [18]. One of the critical aims of $\mathrm{KM}$ is to offer employees access to knowledge using KM tools and make knowledge acquisition easier [22]. Knowledge forms and characteristics, KM frameworks, and infrastructure were all topics of previous KM research. KM initiatives were intended to provide considerable impact to the organizations, mainly assisting in developing corporate strategy and business process engineering and attaining a competitive edge $[17,22]$. KM practice has been further developed to enhance sustainable knowledge-intensive business activities within knowledge-intensive organizations, e.g., [19]. In this context, KM is the method of extracting value from an organization's intellectual capital, which includes three forms of resources: people, structure, and clients. The four primary processes are knowledge discovery and acquisition, knowledge transfer, knowledge integration, and knowledge development [25]. People, processes, technology, and the environment are organized, planned, scheduled, monitored, and deployed systematically within KM infrastructure, with suitable targets and feedback mechanisms. These activities aim to make generating, preserving, exchanging, discovering, acquiring, utilizing, and evaluating knowledge and new concepts easier, to achieve strategic objectives and sustainability goals, such as improved competitiveness or performance [26]. KM includes any activity associated with the capture and diffusion of knowledge within the organization. One of the primary goals of KM infrastructure is to provide access to organizational knowledge sources to improve employees' decision making. Hence, it is a concerted effort to improve the way knowledge is created, delivered, and used. Organizations should adopt a management strategy that addresses each of these three key activities [22].

\subsection{Knowledge-Intensive Organizations and KIBP}

Knowledge-intensive organizations operating in today's business environments face several kinds of challenges that stem from the characteristics of their business processes and environments [11]. These challenges include, for example, highly dynamic business environments, complicated intellectual work at all levels of the company, efficient use of information and communication technologies, and a rapid pace of information and knowledge renewal. Biotech firms, professional service firms, software firms, and the pharmaceutical sector are examples of highly developed knowledge-intensive organizations that rely mainly on the skills of their staff. [27]. In these organizations, organizational structures are based on processes or projects and can be changed flexibly to best serve the business objectives [27]. Knowledge intensity measures the extent to which an organization relies on its activities and outputs as a source of competitive advantage [16]. A process is knowledge-intensive if its value can be created by using knowledge assets to fulfill the process [28]. Because of the changing nature of their environment, business processes in knowledge-intensive sectors are dynamic [29]. Business processes should accommodate modifications such as adding a new operation, substituting existing activities, and reordering numerous activities [30]. Traditional static business processes, on the other hand, are designed to depict predetermined processes and lack flexibility. Furthermore, dynamic modifications are typically made in an operational context [31]. Business process dynamicity can range from relatively static business processes, for which all operations and their tasks are predetermined and presented in a flowchart and, therefore, cannot be changed, to full-stack dynamic business processes, in which each operation is selected from a predetermined set of operations or even distinguished as requested by rules. Business rules outline how knowledge experts can proceed with tasks in knowledge-intensive processes [32]. Nevertheless, knowledge workers must cope with the uncertainty that traditional business rules cannot adequately address in many business cases. Declarative 
models are used in some knowledge-intensive processes to indicate what should be done, without actually stating how it should be done [31].

Today's knowledge-intensive organizations are mainly based on knowledge workers involved in KIBPs as "raw material" in producing the value of innovative products and services for their customers [33]. Knowledge-intensive organizations face knowledge problems because of the continuous and expanding transfer of knowledge workers within and outside the organization. Employees have tacit knowledge that unfolds and is attempted to be made explicit in related business process improvement projects that aim to increase the efficiency and effectiveness of the business processes [22]. The main effort of KM programs in knowledge-intensive organizations should aim to enhance the KM procedures of capturing, storing, and sharing knowledge workers' knowledge for the sustainable and effective operation of the KIBPs [34]. Knowledge workers spend a lot of time messaging, creating documents, searching for knowledge, and engaging in other knowledge-intensive activities. Despite their extraordinary time commitment, however, knowledge workers have been mostly left to their own devices, with little help from their organizations performing knowledge tasks effectively and efficiently [22].

Knowledge workers can define the process flow at run-time depending on the information available to them in a dynamic knowledge-intensive process, a collection of activities or tasks that do not follow a planned sequence of operations [35]. Knowledge workers decide the sequence of operations in a dynamic process, start and finish activities, assign activities to roles, and complete and terminate process entities during process operation. The information and knowledge flow of KIBPs is not structured, and it can evolve during process execution [22]. The main properties common to KIBPs, as summarized by [28], are a diversity of information sources and media types, variance and dynamic development of organizational processes, requirements of creativity, requirements of innovation, and complex decision-making processes.

In recent years, the literature has introduced many approaches to the digital transformation of business processes. Examples include the nine-phase approach, which provides "the combination of innovation, flexibility and continuous updating throughout the digital transformation of business processes" [36], and a methodology that "integrates ideas from continuous process improvement, business process reengineering, and business process benchmarking" [37]. Existing business process improvement approaches lack methodologically sound support for their users [36]. These users perform knowledge-based tasks characterized by a high level of complexity and exceptions, weakly-structured processes, informal networks and communities, and a high level of expertise and skills. In the context of KIBPs, KM suggests focusing on enhancing the efficiency and sustainability of knowledge by linking KM efforts to the value chains of organizations [38].

\subsection{KM Infrastructure}

$\mathrm{KM}$ is concerned with the process of managing organizations in terms of acquiring, transforming, applying, and preserving knowledge, provided that the appropriate infrastructures are in place to meet organizational goals [39]. KM infrastructure is necessary to maintain actual and valuable explicit and implicit knowledge in the organizational network. Organizations develop their KM infrastructure to respond quickly to the complexities of a fast-changing environment, which becomes a critical factor that intensifies the organizational competency by shortening the time required to develop competencies [40]. Infrastructures are challenging to research due to their complexity, and their socio-technical components are often hidden [41]. KM infrastructure combines social and technical perspectives and includes three main components that $\mathrm{KM}$ research in any organization should take into consideration: knowledge processes, organizational culture, and information technology [39].

Knowledge processes have many frameworks, weakly specified definitions, shapes, and forms, with no commonly agreed-on definitions in the literature. The literature does, however, provide a comprehensive list of KM-related procedures that facilitate organiza- 
tional KM and support organizations in their attempts "to generate, create, acquire, test, organize, use, and disseminate knowledge as well as transform the expertise of the organization into important knowledge for administrative activities, such as decision making, strategic planning, learning, and problem-solving" [42]. KM infrastructure supports KM processes by identifying which "knowledge is retrieved, applied, protected, and stored to become easy to use" [39].

Culture has become increasingly important for organizations in the past 20 years. Studies in KM underscore the inseparable relationship between effective KM and organizational culture [22] and address the great value of the implicit relations between organizational culture and performance [39]. The motivation of knowledge workers to share knowledge is the main issue of corporate culture [35]. While organizational cultures supporting knowledge sharing offer essential, competitive advantages, different cultural backgrounds of team members, such as different ethnicities, national cultures, gender, or roles, create a context of cultural complexity and might impede knowledge sharing [39]. Organizations should adopt an entrepreneurial culture when establishing KM activities [43]. KM-related organizational culture should support workers' readiness to provide complete, undistorted, and verifiable information, their ability to convey and interpret data without being swayed by elements unrelated to the topic at hand, such as position and status, and their acceptance of responsibility for their actions and their consequences and for learning from such consequences. KM-related culture should encourage workers' aspiration for team success and enhance trust among people. It should also encourage workers' beliefs on how personal success is influenced by sharing personal knowledge and experiences and on how sharing personal knowledge may provide the power to influence organizational decisions [44].

Information technology (IT) aims to facilitate the execution of key tasks that knowledge workers must perform. KM technology can enhance these essential tasks by offering incredible speed and quality and lowering costs [22]. KM systems can support corporate $\mathrm{KM}$ processes in various ways by leveraging various information technologies [45]. These systems provide technical platforms on which organizational knowledge activities may flow and intersect, providing users with a channel to create, acquire, document, share, transfer, and apply knowledge to meet workers' needs. By doing so, KM systems accelerate knowledge capture and exchange, enabling them to occur readily, freely, and openly between relevant people in organizations. Any effective implementation of KM ideas and methodologies will require a sound IT infrastructure. Information technology, artificial intelligence, data mining, and knowledge modeling are the most commonly used KM techniques and technologies, which are applied in many research and problem domains [46]. The comprehensive list of updated KM technologies that facilitate organizational KM includes information exchange and collaboration systems, data analytics and decision support tools, Web content management, Web-blog, mobile technology, project management tools, and more [47].

\subsection{KM Infrastructure as an Enabler of KIBPs}

Knowledge is a critical component of the business process, with KM as a meta-process of business processes [13]. According to this viewpoint, KM serves as a producer, accelerator, and promoter of value preposition at the strategic level. KM improves business process performance by improving and accelerating the creation of value. Process management systems are linked to knowledge creation [48], with KM serving to enhance business outcomes and sustainability of organizational business processes [49]. With digitization, an increasing amount of data and information is generated within a shorter period, which must be collected and processed into organizational knowledge that increases competitiveness. A well-grounded knowledge base can be established to adapt and optimize business processes using various data sources. In other terms, KM serves as a foundation for better process management, modification, and adoption [50]. Knowledge-based process management should combine two strategies: controlling the organization's processes to enhance them and leveraging its knowledge assets. The formation of intangible knowledge assets 
is considered at every stage of the operational process deployment, and KM procedures become a vital task and challenge for any KIBP [15].

To fully realize the value of KM in KIBPs, knowledge must be made available not just during the analysis and design phases of business processes but also during their implementation. While intentionally building business processes to use and support KM, KIBP-oriented KM is required [22]. The literature review reveals that current KM infrastructures stand separately from KIBPs and do not deal with knowledge within the context of operational KIBPs. Therefore, applying the existing KM infrastructure frameworks in the context of KIBPs may be incomplete or erroneous because KM solutions are too complicated and require multiple views to support the complexity of business processes. The literature indicates a great need for an integrated multi-perspective KM infrastructure framework for comprehensive, multifaceted KM in KIBPs that manifests the socio-technical KM infrastructure perspective. Such a framework should adequately support the development of a KM infrastructure for KIBPs. This study aimed to bridge this gap by developing a KM infrastructure framework in the context of KIBPs and by demonstrating, via a case study, how the KM infrastructure's components are embedded within the business processes.

\section{Research Method}

\subsection{Research Approach}

$\mathrm{KM}$ is inextricably tied to people due to the nature of knowledge and therefore has sociological components [35], which can be researched following the sociological paradigm that is predominantly qualitative in nature [51]. Such qualitative research can be carried out using the case study approach, which is especially suitable for obtaining complex data, facts, and narrative understandings about a specific phenomenon under investigation, and which can be used to accomplish various research aims, such as providing details for theory generation and validation [52].

The methodological approach guiding our empirical work is based on the grounded theory methodology [52], whose essential idea is to develop a theory inductively from data collected in the investigated field; hence, the theory is grounded in data [53]. The data collected during grounded theory research is inductively coded, with "open, axial and selective coding, until data analysis saturation is reached" [52]. Grounded theory is distinguished from other qualitative approaches by its emphasis on theoretical growth and the continual interdependence of data gathering and interpretation. [52]. The theory created exhibits the collected and analyzed themes that emerged from the research data. The process of consolidating the grounded theory constitutes validation in itself: "Validity is achieved after much fitting of words when the chosen one best represents the pattern. It is as valid as it is grounded" [54], p. 6. In addition, it is suggested to use a variety of data sources, which helps reduce the risks to validity and improve reliability [55]. Accordingly, multiple data sources were used in this research, including interviews, organizational documentation, and field observations. We followed the nine steps of the grounded theory research method adopted from [52], as presented by Pandit (1996) [56]. Pandit's method was applied to a case study to generate a theoretical framework in this research (see Table 1).

Quantitative data were collected using a structured questionnaire as a complementary source. The objective of the quantitative data collection and analysis was to mitigate some of the threats to the validity and increase the generalizability of the results obtained in the qualitative part of the research. The questionnaire was constructed to evaluate the KM infrastructure components that emerged from the qualitative data analysis by examining the expected contribution of each KM infrastructure component to the productivity of the research population, i.e., the knowledge workers involved in KIBP execution. 
Table 1. The process of building a grounded theory [56].

\begin{tabular}{|c|c|c|c|}
\hline Phase & & Step & Main Activities \\
\hline \multirow{5}{*}{ Research design phase } & Step 1 & Review of technical literature & Defining the research question \\
\hline & Step 2 & Case selection & Theoretical (not random) sampling \\
\hline & Step 3 & $\begin{array}{l}\text { Development of rigorous data } \\
\text { collection protocol }\end{array}$ & $\begin{array}{l}\text { Defining themes that delineate the boundaries of } \\
\text { the research question and building an initial guide } \\
\text { for interviews }\end{array}$ \\
\hline & \multirow[b]{2}{*}{ Step 4} & \multirow[b]{2}{*}{ Entering the field } & Collecting and analyzing overlapping data \\
\hline & & & $\begin{array}{l}\text { Using flexible and opportunistic data } \\
\text { collection methods }\end{array}$ \\
\hline Data collection phase & Step 5 & Data ordering & Sequencing events chronologically \\
\hline \multirow{2}{*}{ Data analysis phase } & Step 6 & Data analysis & Using coding and memo \\
\hline & Step 7 & Theoretical sampling & Looking for theoretical replication across cases \\
\hline $\begin{array}{l}\text { Return to Step } 4 \text { (until } \\
\text { theoretical saturation) }\end{array}$ & Step 8 & Reaching closure & Looking for theoretical saturation when possible \\
\hline Literature comparison phase & Step 9 & $\begin{array}{l}\text { Comparison between emergent } \\
\text { theory and extant literature }\end{array}$ & $\begin{array}{l}\text { Making comparisons with conflicting and } \\
\text { similar frameworks }\end{array}$ \\
\hline
\end{tabular}

\subsection{Case Selection}

The aim of this research was to develop a KM infrastructure framework of KIBPs for knowledge-intensive organizations. To this end, collaboration was initiated with a large international software company that employs several thousand software developers worldwide and has its headquarters in the United States, with about 150 offices in 45 countries. We chose the company's support division (denoted hereinafter Support) as the research field for the case study. Support has over 70 technical centers in more than 20 countries, where Support specialists work around the clock to assist customers in various time zones and languages. Support encompasses two departments called Level 1 and Level 2. Level 1 consists of many semi-technical employees who either resolve customer claims or refer them, as required, to Level 2, which consists of technical product specialists. The purpose of this structure is to enable Level 1 to handle repetitive and simple customer claims that do not require code development for their solution and can be provided by lower-cost resources, thus reserving expensive and scarce engineers located in Level 2 for more complicated and newly introduced problems. The customer claim resolution process operated within Support and involving Support engineers, served as the KIBP our case study focused on.

The necessity of non-random theoretical sample selection is emphasized by grounded theory [56]. The selection process should ensure that the research question's most important issues are addressed (Table 1, Step 2). We created the following three criteria for selecting Support teams to be included in our case study to attain this goal and selected teams that met at least two: (1) the teams should execute claim resolution; (2) the teams should be located at different sites and in different countries, representing different business environments in terms of the three KM components: processes, culture, and IT; and (3) the teams should provide customer support for different products. Based on these criteria, data were collected from 16 Support teams located in the following countries- Israel, France, the UK, and the United States. Six teams differ from the rest because they originate from other organizations recently purchased by the studied organization. These teams use independent IT infrastructures and self-defined management styles and performance measurement systems. This diversity in research environments contributes to the external research validity. 


\subsection{Data Collection}

Semi-structured interviews and associated documentation were used to collect data (i.e., organizations' annual reports, Support internet site). Using multiple methods and data sources provides greater construct validity in case-study research and offers an opportunity to triangulate findings to deepen understanding [51]. The interviews were collected and analyzed according to the KM requirements engineering methodology (KM-REM) [57]. KMREM integrates methods from multiple disciplines-requirements engineering, knowledge auditing, and system modeling - to complement each other to generate a comprehensive methodology for KM-oriented requirements engineering (RE). As an integrative, sociotechnical methodology, KM-REM enables comprehensive auditing of the organizational KIBPs and an inspection of the knowledge sources of each process in terms of their creation, sharing, and usage from both the technical and the social perspectives. The social aspect of KM-REM deals with identifying the human-related concerns that impact knowledge creation, transfer, sharing, and reuse, focusing on communications and organizational culture. The technical aspect of KM-REM includes methods and tools for storing, transferring, and facilitating access to knowledge. This comprehensive view goes beyond previous KM audit methods, which typically address knowledge separately from the processes in which it is created and used and the technology it is captured with. KM-REM provides descriptive definitions and principles and concrete tools for eliciting and analyzing relevant data from technical and social perspectives. In this sense, KM-REM addresses knowledge processes, technology, and culture and provides descriptive, procedural, and practical tools and guidance for a comprehensive socio-technical analysis of KM requirements in the organization.

In the first round of data collection, we conducted 14 interviews with Support managers and engineers from two countries. The interview questions were updated according to the concepts, categories, and linkages that emerged from the data collected and processed. Ranging from broad to specialized, the emergent data analysis guided us to change question phrasing from more straightforward to more elaborate and refined (see the final set of interview questions in Appendix A). In addition, as the study progressed, we had to make a more deliberate selection of new respondents due to the overlap between data collection and analysis. We discovered categories that warranted further research due to new concepts that developed from the data analysis process. Following this, we chose additional respondents (since saturation had not yet been reached) and conducted a second round of interviews, including those who had already been interviewed. Thus, in the second round, in addition to interviewees from the first round, we interviewed and observed 15 additional engineers in the UK and the USA. The extra interviewees were chosen based on their familiarity with the Support processes and procedures. All interviews were audio-recorded and transcribed, and respondents' names and other identifying details were changed for confidentiality reasons.

Following the interviews and previous research suggestions, a structured survey questionnaire was designed for research result validation (see Appendix B). The questionnaire included the core categories and sub-categories that emerged in our study from the qualitative analysis of the KM infrastructure in the context of KIBPs. The questionnaire was distributed in three cycles. The first was defined as a pre-pilot aimed at refining the survey questions. Six engineers from three support teams completed the survey in the presence of one of the researchers, thus enabling clarifications and discussions about the questions. All unclear questions were refined based on the respondents' comments. The second round, defined as the pilot, included distributing the survey questionnaire to 25 engineers from various support teams, 16 of whom responded. The original questionnaire included 67 items. Following the pre-pilot and pilot cycles, several items were eliminated as they were too specific and irrelevant for most teams. Finally, 19 items were carefully selected for the final survey to ensure they could be completed within a reasonable time frame. This final version was sent to 194 engineers; 112 (57.7\%) submitted a complete response. 


\subsection{Data Analysis}

Following the data collection stage, we created a detailed description of each Support department based on interviews and documentation (Step 5). Then, numerous grounded theory techniques were used (Steps 6 and 7). First, we selected ideas and related features from the collected data using an open-coding technique, which led to the emerging of categories from the data. The data were then coded using either emic or epic coding: Emic codes consist of labels taken directly from phrases used by the respondents. In contrast, epic codes are labels created by the researchers according to the meaning in the text. Table 2 presents several examples that demonstrate several concepts defined during the open-coding step.

Table 2. Examples of open coding.

\begin{tabular}{|c|c|}
\hline Phenomenon & Concept \\
\hline "The question is what knowledge to write about?" & Knowledge creation policy \\
\hline $\begin{array}{c}\text { "I think that we should have a knowledge creation } \\
\text { policy on what kind of information is valid for } \\
\text { knowledge creation ..." }\end{array}$ & Knowledge creation policy \\
\hline "Documents are scattered in many places" & $\begin{array}{l}\text { Duplication of knowledge } \\
\text { storage repositories }\end{array}$ \\
\hline $\begin{array}{l}\text { "We have many versions of documents, caused by } \\
\text { duplication of knowledge storage repositories" }\end{array}$ & $\begin{array}{l}\text { Duplication of knowledge } \\
\text { storage repositories }\end{array}$ \\
\hline $\begin{array}{l}\text { "Managers should apply best practices for work } \\
\text { method modifications" }\end{array}$ & Work method modification \\
\hline
\end{tabular}

During the open coding, we identified 29 concepts, which were next categorized. We outlined the categories based on the collection of similar concepts derived from grouping concepts at a higher abstraction level [51]. Table 3 demonstrates this through the example of the Knowledge Development category, which emerged following the grouping of related concepts.

Table 3. Example of establishing a category from its concepts.

\begin{tabular}{cc}
\hline Concepts & Category \\
\hline Operational knowledge creation policy & Operational knowledge capture \\
Operational knowledge categorization & \\
Customer-oriented operational knowledge creation & \\
\hline
\end{tabular}

Next, we applied axial coding to outline core categories and sub-categories of the categories revealed in the open-coding stage. Core categories rarely exist in the open coding scheme; instead, they result from a higher level of analysis of the categories that emerged during open coding. The axial coding led to an understanding of the interrelations between the emergent categories. The first theoretical propositions were created at this time, and the preparation of the study insights followed.

Once the core categories were formed, the rest of the interviews authenticated these categories. We further monitored the results of each data collection and analysis cycle. We determined whether the categories were stable by constantly comparing cases and categories until they were theoretically saturated [51]. We sought to examine the internal consistency of the structure of the categories and characteristics conceived in each iteration. The emergence of new concepts that did not fit into the existing categories and attributes pushed us to reevaluate the emergent model and conduct further interviews. These further interviews allowed the categories, their attributes, and relationships to be further developed and understood. When reassessments produced no new categories, subcategories, or 
questions about existing ones-in other words when theoretical saturation was reachedthe interplay between data and concepts came to a stop (Step 8). A literature comparison phase is suggested in Step 9 of the adapted form of grounded theory, in which competing or similar frameworks are systematically contrasted with the emergent conceptual model. In our example, we compared our conceptual model to current KM infrastructure models, and some interesting findings emerged that led to our proposed KM infrastructure framework. Finally, the grounded theory results were evaluated through the survey analysis results.

Data analysis of the survey was carried out at the organizational level by calculating average rates for each question, which allowed us to prioritize the revealed problems, providing Support managers with a valuable tool for effective decision making regarding solutions for highly prioritized problems.

\section{KM Infrastructure Framework}

\subsection{KM Infrastructure Categories}

The qualitative analysis led to 18 emergent KMIF categories: 5 core categories and 13 sub-categories of KM infrastructure in the context of KIBPs. These categories deal with two main types of knowledge in the context of KIBPs revealed in our research: operational knowledge and formal knowledge.

Operational knowledge refers to knowledge that is developed, recorded, and then utilized directly within KIBPs. During the execution of the business process, engineers cope with new problems and various customer and partner demands, create new knowledge, and may reuse existing knowledge that helps them execute their tasks. In this scenario, Support engineers are a source of new knowledge in terms of skills, as well as specific know-how and abilities in the area of claim resolution, which could be valuable to other engineers and product managers. By capturing and utilizing this valuable operational knowledge, claim-resolution processes may be streamlined, and the "reinventing the wheel" phenomenon can be avoided. The engineers' experience is externalized through defined KM methods included in the claim-resolution processes to improve organizational learning inside the Support division. In the Support case study, the operational knowledge is managed within the CRM system.

Formal knowledge refers to knowledge created, stored, assimilated, and disseminated outside the business process. Nevertheless, formal knowledge influences the knowledge available within the business process, which in our case study refers to the ability of Support engineers to resolve customer claims quickly and effectively. This knowledge includes formal product information, lessons learned, or best practices and is managed mainly within document management systems such as portals, file servers, and personal PCs.

Following the definitions of operational knowledge and formal knowledge, we developed two respective types of knowledge procedures: operational knowledge procedures and formal knowledge procedures. Similarly, the research results divided the IT systems into two categories: operational systems and knowledge systems. The research also revealed knowledge workers' training and KM-related culture as core categories of KMIF. Table 4 lists and describes these core categories and their sub-categories.

\subsection{Overview of the KMIF}

Figure 1 illustrates the main contribution of this study, a conceptual model of a KM infrastructure framework that seeks to support the processes of defining, establishing, and monitoring knowledge procedures in the context of KIBPs, thus providing a guidance opportunity to enhance the business outcomes and support sustainable goals of the KIBP execution. Formed by systematically executing the eight steps of the adapted grounded approach [56], this model guides the integration of KM practices into organizational KIBPs, supported by a KM infrastructure that has been adapted to KIBP needs. The model is composed of constructs (categories), properties, and relationships. The model encompasses two complementary building blocks: operational KM-oriented components and formal KM components. The operational block includes a group of operational categories that facilitate 
effective KIBP execution. The formal block includes a group of organizational categories and the adaptation and integration of formal KM components into the operational work environment as a facilitator of the operational block.

Table 4. KMIF categories in the context of KIBPs.

\begin{tabular}{|c|c|c|}
\hline Core Category & Sub-Category & Sub-Category Description \\
\hline \multirow{2}{*}{$\begin{array}{l}\text { Operational knowledge procedures } \\
\text { Deal with knowledge procedures that } \\
\text { are directly involved in } \\
\text { claim-resolution processes }\end{array}$} & $\begin{array}{c}\text { Operational } \\
\text { knowledge capture }\end{array}$ & $\begin{array}{l}\text { A set of procedures that deal with knowledge } \\
\text { capturing during the execution of } \\
\text { claim-resolution process tasks directly within the } \\
\text { operational environment. }\end{array}$ \\
\hline & Operational knowledge access & $\begin{array}{l}\text { A set of procedures that allows engineers to } \\
\text { access useful knowledge for claim resolution } \\
\text { directly within the operational environment. } \\
\text { This includes processes such as real-time } \\
\text { communication among engineers and searching } \\
\text { and retrieving operational documentation. }\end{array}$ \\
\hline \multirow{3}{*}{$\begin{array}{l}\text { Formal knowledge procedures } \\
\text { Deal with knowledge procedures that } \\
\text { are conducted outside the } \\
\text { claim-resolution process. The related } \\
\text { knowledge, however, should be used } \\
\text { during the claim-resolution process }\end{array}$} & Knowledge development & $\begin{array}{l}\text { A set of formal learning procedures executed by } \\
\text { engineers that aims to externalize personal } \\
\text { knowledge by analyzing mishaps and failures, } \\
\text { best practices, and lessons learned. These } \\
\text { procedures include creating formal } \\
\text { documentation of product-related information } \\
\text { that helps engineers resolve claims. }\end{array}$ \\
\hline & Knowledge assimilation & $\begin{array}{l}\text { Refers to the use of organizational experience } \\
\text { and practices, systematic modification of } \\
\text { procedure instructions and work methods by } \\
\text { applying mishaps and failure analysis, and } \\
\text { developing training materials based on lessons } \\
\text { learned and best practices. }\end{array}$ \\
\hline & Knowledge dissemination & $\begin{array}{l}\text { A set of procedures that help engineers obtain } \\
\text { useful knowledge for claim resolution outside } \\
\text { the operational environment. This includes } \\
\text { formal meetings among engineers for } \\
\text { knowledge transfer, the rotation of engineers } \\
\text { among teams, and mentorship. }\end{array}$ \\
\hline \multirow{2}{*}{$\begin{array}{l}\text { Knowledge worker (engineer) training } \\
\text { Deals with training procedures aimed } \\
\text { at increasing the level of } \\
\text { professionalism and skills of engineers } \\
\text { involved in the claim-resolution process }\end{array}$} & Group training & $\begin{array}{l}\text { A set of procedures, such as training on new } \\
\text { products, releases, service packs, and other } \\
\text { materials, provides engineers with the means for } \\
\text { solving problems quickly and effectively. }\end{array}$ \\
\hline & Self-training & $\begin{array}{l}\text { The aims of self-training are identical to those of } \\
\text { group training. Still, Support allocates defined } \\
\text { work time and provides user-friendly training } \\
\text { packages for self-training to enhance engineers' } \\
\text { ability to use organizational information systems } \\
\text { and product-related materials. }\end{array}$ \\
\hline \multirow{2}{*}{$\begin{array}{l}\text { KM-related culture } \\
\text { Deals with the cultural environment } \\
\text { required for the claim-resolution } \\
\text { process to encourage engineers to } \\
\text { contribute knowledge }\end{array}$} & $\begin{array}{l}\text { Rewards for } \\
\text { knowledge contribution }\end{array}$ & $\begin{array}{l}\text { Refers to the various "reward programs" that } \\
\text { include financial incentives or recognition } \\
\text { programs introduced to encourage engineers to } \\
\text { contribute knowledge. }\end{array}$ \\
\hline & $\begin{array}{l}\text { Consideration of } \\
\text { failure analysis }\end{array}$ & $\begin{array}{l}\text { Refers to the necessity to create and maintain an } \\
\text { open environment in which engineers are not } \\
\text { afraid to confess to mistakes and failures. }\end{array}$ \\
\hline \multirow{2}{*}{$\begin{array}{l}\text { Information systems (IS) } \\
\text { Deals with all relevant IS involved in } \\
\text { the claim-resolution process }\end{array}$} & Operational IS & $\begin{array}{l}\text { Refers to the IS that are directly involved in the } \\
\text { execution of the claim-resolution tasks. }\end{array}$ \\
\hline & KM-related IS & $\begin{array}{l}\text { Refers to IS that are external to the process, such } \\
\text { as organizational portals, team websites, search } \\
\text { engines, and document management systems. }\end{array}$ \\
\hline
\end{tabular}




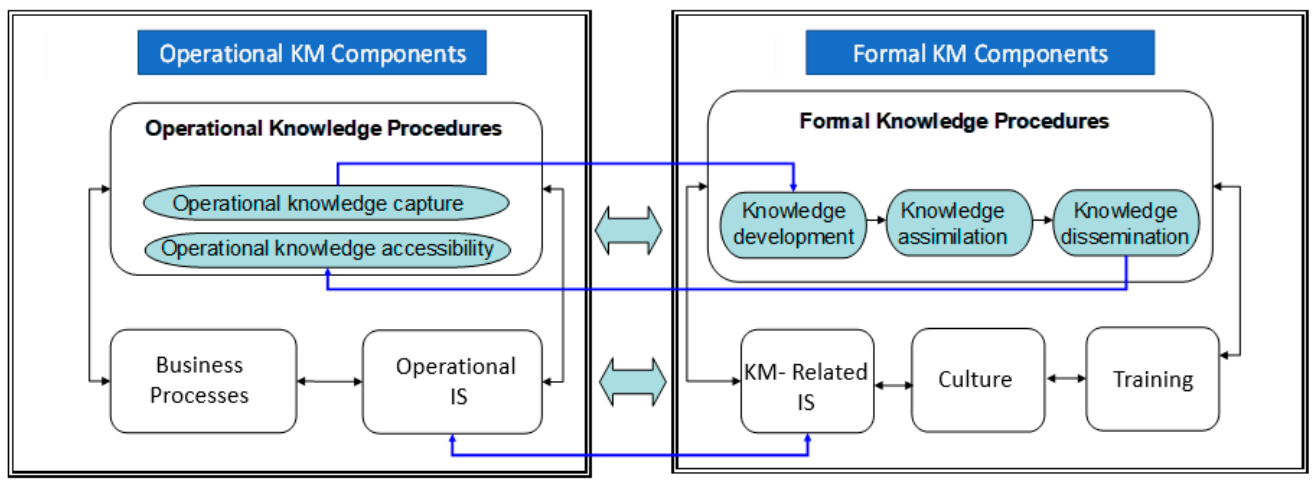

Figure 1. KMIF-KM infrastructure framework.

\subsection{Operational Block}

The operational block encompasses three main categories: operational knowledge procedures, KIBPs, and operational IS. It places a premium on knowledge workers' adherence to KIBP execution standards as a starting point for integrating organizational knowledge assets into KIBPs at the operational work environment level. The formation of the operational block categories and their interaction is a key component of our approach, providing a framework for developing a KM project. Operational knowledge procedures drive KIBPs, while operational IS can consolidate organizational knowledge into the operational work environment. Operational knowledge procedures deal with knowledge procedures that are directly involved in the KIBP. In the context of the Support case study, operational knowledge procedures deal with knowledge procedures that are directly involved in the claim-resolution process. This category consists of two sub-categories: operational knowledge capture and operational knowledge access.

The Support case study highlighted the essential role of operational knowledge capture. Engineers generate and collect a lot of new information on customers, products, and third-party partners during the claim-resolution process. Many engineers remark that they have no criteria for documenting operational knowledge or storing it. Due to the time constraints they experience at work, they find it challenging to pick what expertise to document:

"The question is what knowledge to write about?"; "I think that if we had more information and guidance on what kind of information is valid for knowledge creation, it would be useful".

In this case, we propose introducing operational knowledge creation guidance that would contain information about decision criteria. These criteria would guide engineers on what knowledge to document, taking into consideration resources and time constraints. When knowledge is applied to completing a task or solving a claim, it should be recorded. For example, Support engineers can create, edit, or correct a knowledge base record to resolve customer claims. Expanding an existing claim resolution or expanding an existing process is significantly easier to implement and maintain than initiating and defining a new activity. Capturing knowledge when used and the context in which it is used guarantees that the content is valuable and relevant to real-world problems. When a Support engineer understands the claim, they should first look for existing, relevant knowledge. It not only saves the engineer from having to come up with a solution for a claim that has already been resolved in the past, but it also ensures that the engineer has access to the most up-to-date information.

Furthermore, even if the engineer is aware that the claim has been resolved in the past, it is essential to double-check that nothing has changed since the resolution was documented. Support engineers index claims at the start of the process in the actual scenario. According to the engineers, although they generate keywords at the start of the claim-resolution process, many errors are uncovered only after the inquiry is concluded. "Keywords will be updated at the time of claim closure to ensure keywords' value for 
engineers," they propose. We recommend modifying the claim resolution process flow such that the claim's final keyword categorization in the CRM system is updated in the final step of the process to improve the quality of the categorization process:

"We don't have any rules on how to categorize the claims and how to insert the keywords"; "Everyone has their own style, some people use very sparse keywords, and some people just use a lot"; "Manually defined keywords don't work well for finding similar claims and solutions"; "There are no conceptual relationships between claims". Unstructured keyword management is especially difficult for new engineers because their recommendations for claim keywords are usually based on a small range of meta-data values derived from their limited work experience. Engineers would be able to apply standard meta-data for more effective classification if a uniform, cross-organizational taxonomy was established; the taxonomy knowledge base serves as a shared vocabulary for knowledge categorization. Each claim being categorized will be placed in strictly one category. Every engineer educated in that manner will select the same keywords for similar claims, thanks to a keyword management module within the CRM system based on a central organizational taxonomy knowledge base. An additional conceptual label of operational knowledge capture is multilingual operational knowledge creation. Language disparities in the organization create barriers that make it difficult for engineers and customers to obtain critical knowledge. "Sometimes we don't understand the support people from [Continent X]; they put non-understandable keywords". "I have engineers located in [Continent $\mathrm{Y}$ ] and [Continent $\mathrm{Z}$ ], who are very good at putting keywords in and it's easier to work on their claims, but [Continent X] claims are non-retrievable".

To overcome language and cultural barriers, which have been demonstrated to have a significant impact on keyword selection, we recommend that the taxonomy be managed in English (as it is now) and translated into other languages. When an engineer in nation $Z$ categorizes a customer claim, they will pick meta-data in this country's language, linked to the English taxonomy via the taxonomy engine. Customers in country $Z$ will filter solutions using country Z's keywords and acquire solutions worldwide using self-service via their website. Another difficulty is the upkeep of client knowledge on self-service websites. Product information, such as knowledge bulletins and best practices, as well as recurrent claims and their remedies, should be included on such a website. Engineers develop knowledge items following each claim resolution. This method necessitates copying a large amount of data from the CRM system to the self-service website, posing knowledge generation challenges. "The process of creating knowledge item is not embedded within the claim resolution process"; "The leap from a claim documented in the CRM system to the knowledge item creation system is a completely manual process. It is slow, and the process is redundant"; "Many knowledge items are not created because engineers don't have time to duplicate data, don't remember to do it, and require a long setup time to reproduce what they have previously done".

When knowledge items for the customer's self-service website are created as part of the claim-resolution process, they are more successful. We propose that knowledge item creation be generated automatically from a claim-resolution page within the CRM system to enhance this task. As a result, after solving a problem, the engineer will determine whether the solution is novel and should be added to the customers' knowledge base. If this is the case, the engineer will automatically construct a knowledge item using a predetermined format we designed for Support. The engineers mentioned the knowledge quality issue in this context: "Engineers write knowledge items, with no approval process". Thus, we provided the flow for knowledge approval by the defined responsible person, who approves and forwards knowledge to an administrative IT team that, in turn, publishes it on the customers' website.

The second sub-category of operational knowledge procedures, operational knowledge access, is a set of procedures that allow engineers to obtain useful knowledge for claim resolution directly within the operational environment of KIBPs following business task execution. This sub-category includes processes such as real-time communication, 
searching, and retrieving. The vital issue in this category is knowledge sharing. During the claim-resolution process, engineers from different organizational levels require knowledge to resolve a specific issue. Engineers say that every product line manages self-created knowledge in its own way, with its own templates and settings. Engineers claim that searching for locally managed knowledge is incredibly tough within internal support-level databases without the help of an engineer from that business unit.

"We must engage with both teams (Level 1 and Level 2) to obtain valuable information".

Most existing collaboration tools on the market support unstructured collaboration, and there is little capacity to incorporate them into an organization's current support processes. Traditional CRM programs, which are designed for problem monitoring, do not manage collaboration well, especially across organizations; as a result, most of the de-facto collaboration takes place outside the CRM system. "In the current situation, informal collaboration within Support takes place in the form of face-to-face conversations, e-mails, phone calls, and instant messaging. Relying on these informal methods of collaboration has several drawbacks"; "Information is usually transferred verbally between me and the principal engineer"; "The field team guys provide information face to face".

While CRM systems employ an escalation-based strategy that assigns one person to each task, the truth is that many circumstances necessitate the collaboration of numerous engineers. Modern technologies can help enable informal collaboration between teams and levels. Specific technological solutions can help shorten the time it takes to gather the details of a claim and facilitate conversation. A discussion can be recorded and transcribed using voice-to-text technology, for example. Automatic indexing and speaker identification can recognize the speakers in a transaction and tag discussion portions accordingly, perhaps identifying difficulties and offering advice or resolution. Key terms can be extracted, and associated content can be found using claim extraction and linking in the knowledge base. Many of these features are now available as native capabilities of the support services provider. Machine learning capabilities can also be added to the knowledge environment via cloud-based point solutions such as Microsoft Azure Cognitive Services, Amazon Comprehend, and Google Cloud AI Platform. In several countries, Wiki is used as a collaborative tool by Support teams. Engineers find Wiki to be an efficient platform for knowledge sharing in certain situations: "I find it useful to use the Wiki of our development team when trying to resolve a claim". Establishing a knowledge collaboration process helps engineers share knowledge to serve enhanced solutions and elaborate production processes. By using a cross-organizational structured document management system, formal collaboration can be realized, which provides all relevant engineers access to the relevant documentation based on permission management. To improve knowledge availability, such document management systems replace existing non-connected file servers. The organization can also support this activity by providing well-defined information storage guidelines, which will prevent knowledge from being kept in personal or team environments, allowing it to be transformed into organizational knowledge storage and collaboration. It is, thus, possible to structure these repositories and integrate them within KIBPs.

An additional issue of operational knowledge access is information overload. Engineers are often overwhelmed by the amount of information they need to review to identify specific content to help their claim resolution. Moreover, many mission-critical information sources are not indexed by the central search engine, and thus engineers are forced to look for knowledge from multiple sources.

"It is time consuming to find the information you need". "There are too many places to look for possible information. I spend a lot of time running multiple searches in different intranet sites because the info is not consistently logged".

The research results demonstrate the important role of the operational block in facilitating KIBPs. Operational knowledge procedures were identified as an inherent part of the business process (the claim-resolution process in this case study), integrated directly into the operational business process environment. Operational knowledge procedures involve 
various strategies, practices, and mechanisms that can be applied in knowledge-intensive organizations. For example, the process of capturing claim data during the claim-resolution process differs from capturing best practices and lessons learned knowledge that can occur outside that resolution process.

We propose introducing KM procedures within the operational environment (in our case study, a CRM system), which is currently limited to information structuring and retrieving. Since the addition of KM-supported features to the existing operational IT is required to provide a valuable knowledge process, embedding operational knowledge activities within the business process environment may improve knowledge accessibility and reuse.

Figure 2 presents the results of the operational knowledge processes survey items. These results indicate that about $69 \%$ of the respondents believe that facilitating knowledge indexing within the CRM system, knowledge source accessibility within the work environment, knowledge creation guidance, and knowledge retrieval would significantly improve their work quality.

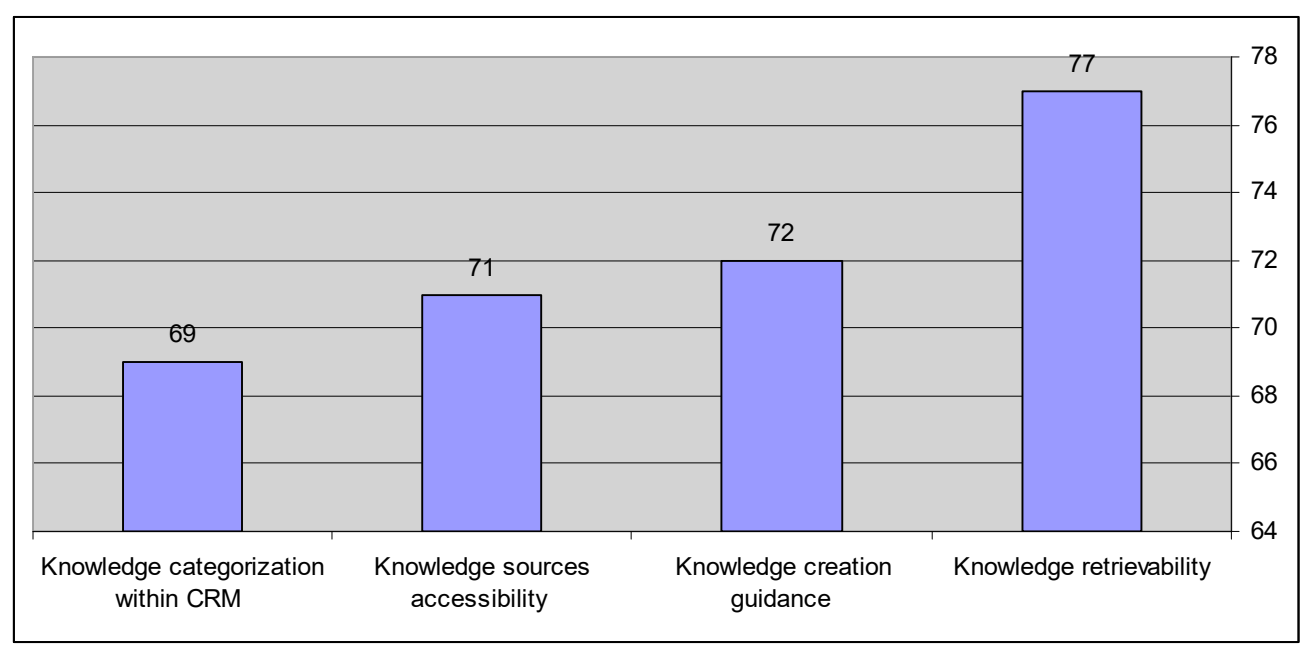

Figure 2. Results of operational knowledge processes survey (in percent).

\subsection{Formal Block}

The formal block encompasses four main categories: formal knowledge procedures, culture, training, and KM systems. Formal knowledge procedures represent a set of independent, stand-alone processes that are performed to provide innovative knowledge (i.e., best practices, lessons learned, up-to-date training, formal product documentation) to support engineers involved in KIBPs. Formal knowledge procedures deal with knowledge development, knowledge assimilation, and knowledge dissemination, as described in Table 2. The role of KM systems is to support formal knowledge processes, providing content and document management, chats, Wiki, and other capabilities.

An additional formal block category is an organizational culture that facilitates the execution of KM procedures. The research results demonstrate the important role of rewards for knowledge contribution in the domain of business processes. Another cultural element is the objective analysis of failures that requires creating and maintaining an open environment in which engineers are not afraid to confess and openly discuss their mistakes and failures. Training of knowledge workers can increase the engineers' professionalism and ability to execute tasks effectively. It requires developing appropriate training programs for support engineers to attract and retain them, elevate their performance, and thereby enhance the outcomes and support sustainable goals of the KIBP. The emergent categories of the formal block, their properties, and their interrelation are vital aspects of our approach, providing a framework for developing a KM infrastructure. Unlike the operational block categories, however, the formal block categories that emerged in this study are not novel; 
thus we do not discuss them here in detail (we invite the interested reader to learn more about them in $[22,35,45,46])$. The connection between the operational and formal blocks is bilateral.

On the one hand, the knowledge created within the operational environment is the primary raw material for creating formal knowledge. On the other hand, formal knowledge should be accessible to engineers on demand, from their operational environment, especially during claim-resolution process execution. For example, formal knowledge procedures such as best practices creation and failure investigation can improve operational work methods. Engineers in our case study say that the claim-resolution process, including protocols, instructions, and work methods, has not changed over time or been updated to reflect the findings of past claim investigations, new best practices, or de-briefing of engineers leaving the organization. "I expect that analysis of failures and successes would be followed by modification of procedures, instructions, and work methods".

An additional example of the interconnection between the blocks is formal knowledge creation and its integration within the operational business process. Engineers are dissatisfied with the poor quality of the formal product documentation. They express a widespread belief that product documentation is mainly prepared from the standpoint of the customer. As a result, according to most interviewees, formal product documentation is rarely used. "Usually, information for claim resolution does not exist in the documentation of the product; you try to figure it out yourself". As part of the R\&D process, formal product documentation should provide information on the product's functionality and assist engineers in resolving customer claims. As a result, the Support division should document problems and provide a proper path for problem resolution. Technical information about all aspects of the product should be included in this documentation throughout the product's entire lifecycle. We propose that the formal product content be created while taking into consideration the engineers' needs.

Another example of the interconnection between the blocks is training material developed based on operational knowledge, including lessons learned and best practices from the operational work environment. Engineers expect that "experience-based knowledge will be integrated into educational content as part of the learning and problem-solving processes". We recommend designating an engineer for each area, who will oversee knowledge maintenance in addition to their regular claim-resolution responsibilities. In other words, Support should set aside time to execute knowledge maintenance procedures. Our model and the case study results show that continuous interactions and conversions between KMIF components contribute to KIPB improvement.

The proposed KMIF forms the foundation for enabling and fostering continuous learning and enhancement of KIBP business outcomes and sustainable goals. An organization's entire set of knowledge assets can only be utilized for substantial improvement if an effective KM infrastructure is established. Such infrastructure should consist of social and technical categories, as described previously. Notably, the KM infrastructure should be supported primarily by well-defined knowledge processes. Thus, what is evident is that KM can be supported in the knowledge workers' environment.

Figure 3 presents the results of the formal knowledge processes survey items. More than $69 \%$ of the respondents believe that the formal knowledge processes presented in the graph significantly enhance work quality.

To evaluate current knowledge duplication, we mapped all potential storage locations involved in the claim-resolution process and asked engineers to indicate which knowledge storage they use for claim resolution:

Question: Where (see rows on the left in the table) do you look for relevant information (columns) when you are resolving an issue? You may choose multiple cells for each item.

Table 5 maps the duplicate knowledge sources as revealed from survey participant answers. 




Figure 3. Results of formal knowledge processes survey (in percent).

Table 5. Duplicate knowledge sources.

\begin{tabular}{|c|c|c|c|c|}
\hline & $\begin{array}{l}\text { Customer } \\
\text { Information }\end{array}$ & $\begin{array}{c}\text { Product } \\
\text { Information }\end{array}$ & $\begin{array}{l}\text { Similar Claims and } \\
\text { Solutions }\end{array}$ & New Releases \\
\hline Best practices of services & $6.7 \%$ & $24.4 \%$ & $28.9 \%$ & $17.8 \%$ \\
\hline Support internet website & $6.7 \%$ & $46.7 \%$ & $20.0 \%$ & $26.7 \%$ \\
\hline Customer support website & $8.9 \%$ & $68.9 \%$ & $46.7 \%$ & $64.4 \%$ \\
\hline Consumer knowledge base & $4.4 \%$ & $8.9 \%$ & $37.8 \%$ & $8.9 \%$ \\
\hline Portal 1 & $15.6 \%$ & $13.3 \%$ & $2.2 \%$ & $4.4 \%$ \\
\hline File servers & $2.2 \%$ & $13.3 \%$ & $17.8 \%$ & $22.2 \%$ \\
\hline Portal 2 & $11.1 \%$ & $44.4 \%$ & $75.6 \%$ & $40.0 \%$ \\
\hline Best practices of field team & $2.2 \%$ & $20.0 \%$ & $15.6 \%$ & $6.7 \%$ \\
\hline Portal 3 & $15.6 \%$ & $26.7 \%$ & $24.4 \%$ & $20.0 \%$ \\
\hline Outside resources & $0.0 \%$ & $20.0 \%$ & $35.6 \%$ & $6.7 \%$ \\
\hline Personal computer & $11.1 \%$ & $26.7 \%$ & $31.1 \%$ & $17.8 \%$ \\
\hline CRM mainframe & $77.8 \%$ & $37.8 \%$ & $77.8 \%$ & $42.2 \%$ \\
\hline CRM web & $15.6 \%$ & $6.7 \%$ & $15.6 \%$ & $4.4 \%$ \\
\hline $\begin{array}{l}\text { Talking directly with co-workers } \\
\text { (e.g., phone or face-to-face) }\end{array}$ & $31.1 \%$ & $48.9 \%$ & $64.4 \%$ & $57.8 \%$ \\
\hline Training systems & $0.0 \%$ & $31.1 \%$ & $15.6 \%$ & $20.0 \%$ \\
\hline $\begin{array}{l}\text { Written interactions with } \\
\text { co-workers (e.g., email, text } \\
\text { messaging, forums) }\end{array}$ & $40.0 \%$ & $62.2 \%$ & $71.1 \%$ & $62.2 \%$ \\
\hline Wiki & $4.4 \%$ & $24.4 \%$ & $20.0 \%$ & $17.8 \%$ \\
\hline
\end{tabular}

The results demonstrate that mission-critical information for the claim-resolution process is stored in different locations, depending on the knowledge owners. Engineers should look for solutions to customer claims from various sources, resulting in a map of fragmented and duplicate knowledge assets. For example, $20 \%$ of support engineers search the Support website for similar solutions, $71 \%$ search written communications with co-workers, and 31\% search personal computers. These numbers indicate that engineers search for the same information in different sources. We also asked the engineers regarding their willingness to share knowledge through a collaborative system: 
Question: Are you comfortable sharing your professional experience and innovative ideas within a sharable corporate-wide collaborative system (e.g., portal)? Please choose one suitable answer.

Sixty-five percent of the respondents indicated that they feel comfortable collaborating through the portal and sharing personal knowledge for reuse by others. Thus, establishing expert support via intranet can serve support engineers corporate-wide. We further asked our respondents about training activities provided to engineers by the organization. Figure 4 presents the results of the knowledge workers' training survey. Results reveal that more than $67 \%$ of the respondents believe that systematic group training and self-training would significantly improve work quality.



Figure 4. Results of knowledge workers' training survey (in percent).

An additional set of questions deals with KM-related culture (results are presented in Figure 5). Only half of the respondents believe that developing an atmosphere of constructive criticism would significantly improve work quality. This is a surprising result because this kind of cultural barrier significantly impacts knowledge transfer within the organization [28]. One possible reason for this outcome is that those engineers already feel that the current atmosphere is adequate.

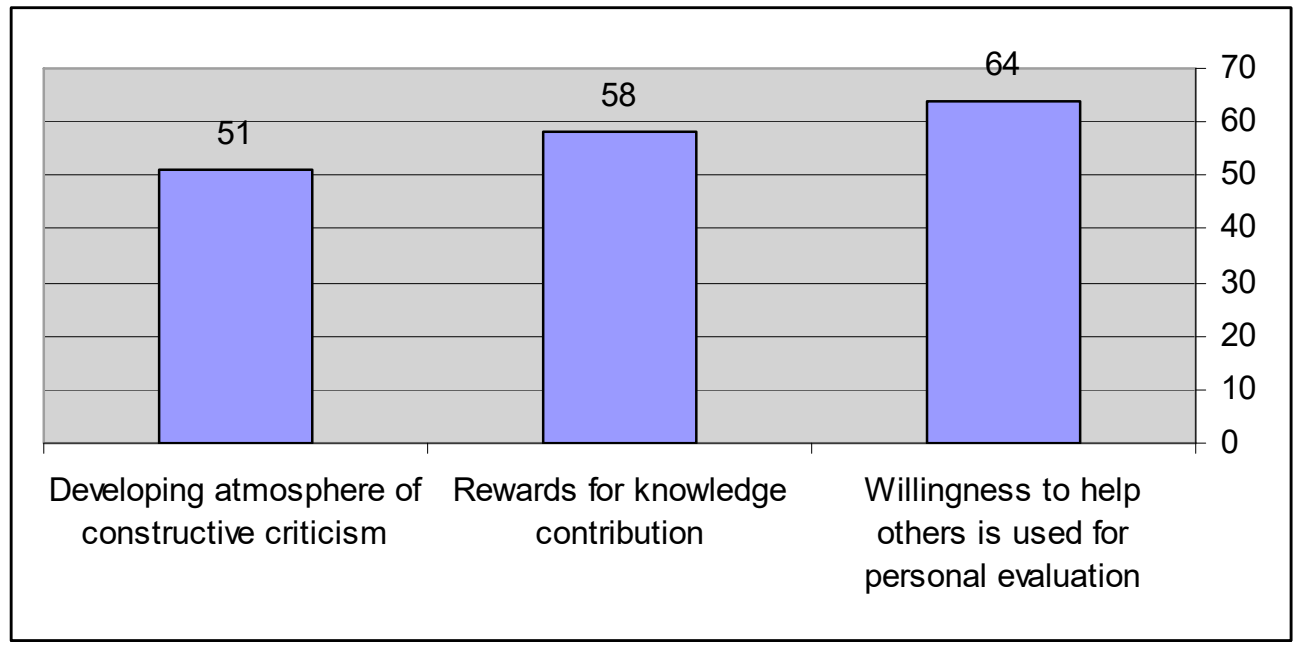

Figure 5. Results of KM-related culture survey (in percent).

\section{Discussion}

The main contribution of this paper is the proposed KM infrastructure framework (KMIF) for enhancing business outcomes and supporting the sustainable goals of KIBPs, as expressed in a conceptual model (Figure 1) that combines socio-technical components. The framework guides the construction of a KM infrastructure designated to support 
defining and monitoring organizational knowledge assets integrated into the operational environment of knowledge workers, thus supporting the effective execution of KIBPs.

One of the strengths of the conceptual model proposed here is the synergy between two building blocks: the operational block and the formal block. While the operational block includes components that are involved directly in the execution of the business process, facilitating the effectiveness of KIBP execution, the formal block includes components located outside the operational environment. The model proposes interconnections between these two traditionally distinct processes in a way that provides a multidimensional perspective on organizational KM infrastructure. Once articulated consistently and combined effectively, the two types of components help promote the integration of structured and unstructured knowledge in the operational environment while enhancing the effectiveness of the operational block, thus improving the KIBP and its outcomes.

KMIF contributes to the research and practice of the KM domain as well as the business process management domain by bridging several gaps revealed in the literature on two themes: socio-technical KM infrastructures and KIBP performance. According to the literature review, KM research in the setting of KIBPs is still in its early stages, highlighting the need to define KM infrastructure components in the context of KIBPs and determine how these components might be integrated into KIBP processes. The objective of the current research in this context was, therefore, to develop a KM infrastructure framework for knowledge-intensive organizations to enhance the outcomes of their KIBPs. To this end, we implemented the grounded theory approach and developed a KM infrastructure framework of KIBPs grounded in empirical evidence. KMIF facilitates a holistic approach, encompassing culture, knowledge processes, and technology. This research identified and described a comprehensive list of KM infrastructure components in knowledge-intensive organizations and their interactions in the context of KIBPs.

According to an initial analysis of the KM infrastructure components developed in this research, some of the underlying ideas, such as formal knowledge processes, culture, and training, are in close agreement with the theoretical definition of KM infrastructure. This suggests that the conceptualization of the KM infrastructure components based on data from the field study corresponds to earlier conceptualizations based on existing theory, enhancing the research design's dependability [55]. Nevertheless, the research revealed unique characteristics related to KIBPs for each of the KM infrastructure components. Two main types of knowledge emerged in the context of KIBPs: operational knowledge and formal knowledge. While operational knowledge is created, maintained, and then used directly within the business process, formal knowledge is developed, stored, integrated, and distributed outside the KIBP. Yet, it influences the availability of knowledge workers' knowledge of how to execute their knowledge-intensive tasks quickly and effectively. Comparing the operational knowledge definition with the literature, we found only one researcher who offered an operational definition of knowledge as "the value-endowing meta-resource that arises from thought, reflection, or experience," [55], p. 164, justifying his typology of tacit, codified, and encapsulated knowledge. Our definition differs from [39] in that we focus on the operational knowledge of a specific business process environment since the KIBP requires the delivery of knowledge at the appropriate time and place.

Second, one of the KMIF model's most important features is its ability to raise awareness that implementing a KM project to support KIBP execution cannot be viewed solely as a traditional formal knowledge project that is distinct from knowledge-intensive operational activities. An operational activities-driven KM project must operate well in conjunction with other categories, such as operational IS, business processes, and operational knowledge procedures, especially during the phase involving the definition of relevant knowledge needs. As presented in Figure 1, operational knowledge procedures and formal knowledge procedures are closely linked, thus creating an interconnecting loop between the two. The knowledge captured by an operational knowledge capture procedure during the execution of the business process tasks, directly within the operational environment, should be refined using a formal knowledge procedure to improve its 
accessibility and reusability and returned to be integrated within the operational block. The survey results reveal that retrievability of knowledge is the primary concern of knowledge workers within operational knowledge procedures. It is also worth noting that, for any knowledge-based operations to be successful, the knowledge maintained by organizations must be readily available and retrievable. Knowledge sharing can occur directly between the knowledge provider and the knowledge seeker if knowledge is not maintained in some form that is easily searchable and retrievable. Direct sharing of knowledge is generally more effective than indirect sharing of knowledge because it allows for more in-depth exchanges and investigation of issues that may not have been documented [22]. The knowledge consumer and the supplier may not, however, be acquainted or available at the same moment. Documented information can be available at any time, regardless of whether or not specialists are available. An essential issue in the formal KM process is allocating work time for investigation procedures such as best practice generation and failure inquiry. According to the findings, organizations should set aside time for engineers to analyze failures and document best practices. Internal best practices can be a valuable complement to other improvement methods, many of which focus on finding and correcting issues. As opposed to top-down approaches such as defining standards, bottom-up approaches foster more significant learning inside the organization. More could be achieved if organizations were to implement systematic procedures for identifying and sharing best practices.

As demonstrated in Figure 4, the key element of KM infrastructure culture is that willingness to help others is used for personal evaluation and rewarding. Our findings support the previous one, arguing that culture becomes a resource that organizations can utilize to recognize and respond to changes in dynamic environments [22]. Organizational culture should promote shared values, beliefs, and expectations that govern employee activities, practices, and behavior norms within the organization. Organizational culture is commonly considered an accelerator that can prompt knowledge workers to notice a change and adapt to their expectation of being rewarded for knowledge contribution. Our findings suggest that organizational culture impacts the success of KM, particularly in the generation and transfer of tacit knowledge. The willingness of employees to share knowledge affects the success of KM, and our research demonstrates that cultural elements encourage knowledge workers to contribute knowledge within the organization. Our findings shed light on the role that KM initiatives can play in assisting KIBP execution, emphasizing the need for context-specific KM methods and tools.

A third important result of our research follows the absence of operational activitydriven KM infrastructure themes from the KM literature, which prompted us to apply a grounded theory approach. We sought to learn what function the KM infrastructure plays and could potentially play based on the experience of an organization with a lot of KM practices. We compared our conceptual model to current KM infrastructure models and found some interesting insights using Step 9 of the adapted grounded theory. The formal block is built on a multi-category framework that attributes formal knowledge methods, culture, training, and knowledge management systems equal weight. It is in line with the literature evaluation, which implies that different perspectives on formal knowledge processes are important $[45,58]$. In addition, there is a lack of conceptual models in the literature that deal with operational knowledge. The comparison between the operational block categories - operational knowledge procedures, operational IS, and KIBPs-and the categories in Johannsen's KM model [59] was quite interesting. Surprisingly, these categories are quite like Johannsen's research axes, which offer knowledge codification procedures, IS (as a solution for codification), and business process improvement. After careful consideration, we concluded that our categories were more relevant in a KIBP context than Johannsen's approach [59]. By replacing Johannsen's codification of knowledge with the operational knowledge procedures that emerged in this study, our model extends the scope of the knowledge procedures to the context of the operational work environment, which can easily encompass operational activity-driven KM goals. In addition, by replacing Johannsen's IS (as a solution) with operational IS, we focus on specific IS involved in KIBP 
execution, thus facilitating its usage in relevant KM solutions. According to the grounded theory approach, the operational knowledge processes block generated inductively via systematic data gathering and analysis is a new category that has not been revealed in previous research. By linking the formal block to the operational block, we consider the various socio-technical KM factors intrinsically involved with operational activity-driven KM. In short, Pandits' Step 9 [46] assisted us in acknowledging that, while the similarities between our framework and those presented in the literature support the validity of our schematic design, our framework is comprehensive in terms of the objectives for which it was created: to purposefully integrate KM into the KIBPs and the operational work environment. Various KM infrastructure components can guide organizations in customizing the framework to their business needs and organizational context. Knowledge-intensive organizations can use the KM infrastructure components and framework as a KM roadmap for KIBPs. Our framework contributes to the integration of KM into the operational work environment of KIBPs by demonstrating that the construction of a KM infrastructure necessitates a conceptual framework that considers both technological and social elements.

\section{Limitations and Future Research}

There are certain limitations to this study's findings and to the validity of its conclusions that should be taken into consideration. We analyze the four components of credibility, dependability, confirmability, and transferability [60] using a qualitative approach and discuss the respective limitations arising from the study's settings and methodology.

Our first concern is credibility. The researcher's personal experiences and viewpoint may inject bias into the qualitative research process, affecting the credibility of the research findings [61]. Credibility is also limited by the case-study research methodology we used [51]. In qualitative research, member checking is used to preserve validity to enhance research credibility [62]. Member checking allows the researcher to validate the accuracy of the participants' voices by allowing them to confirm or deny data interpretation [63]. We followed this approach and performed member checking by allowing participants to provide feedback on the interview notes as well as on any inferences formed from the comments. The absence of bias in our reporting and agreement with the interview transcript through member checking were adequate to make this study credible. We further improved credibility by verifying the research findings with survey respondents.

Our second concern is dependability, which is attained when replication of the study using the same or similar participants and contexts produces the same findings. Dependability is recognized if the research process is traceable, clearly documented, and demonstrates to the readers that the findings are reliable and repeatable. The objective of the case study approach is to ensure that any other researcher, following the procedures described by a previous researcher, would arrive at the same findings and conclusions [51]. Following previous research recommendations, our research study ensured an audit trail by presenting the purpose of the study, describing the selection process for the study participants, describing the data collection process, demonstrating how the data were interpreted and analyzed, discussing the research results, and communicating techniques to determine the credibility of the data [62]. We checked the interview transcripts to eliminate any ambiguity or mistakes. We also ensured that the coding was aligned with the actual meaning by constantly comparing data with the codes. We cross-checked codes by employing a colleague who helped us double-check the coding to ensure dependability.

Confirmability is our third concern, and it refers to the degree to which the findings are consistent and repeatable within the study [61]. As the primary research instrument, the qualitative researcher interacted with study participants and oversaw data analysis. The answers were transcribed, and the transcribed data were saved on a shared file server to be used as an audit trail when needed to confirm that the participants' perspectives were represented in the data and research.

Our last limitation is derived from the case study technique that was applied and dealt with the question of transferability. The proposed framework was grounded in a 
single organization, limiting the generalizability of the findings. However, this limitation was mitigated, to some extent, as this case study involved a vast international company, from which we chose 16 different support teams on three continents, six of which have independent business environments and organizational cultures. We, therefore, believe that this sample exhibits a significant degree of transferability [60] to other knowledge-intensive organizations, mainly if differing social norms are considered. Furthermore, if even a single case satisfied the study's goal, it could be judged acceptable [51].

As previously said, sustainability is a necessary but relatively new field in the realm of KIBPs, particularly in the operational environment, which adds a great deal of new knowledge and increases the complexity of operational activities. KMIF appears to offer many potentials to aid firms in dealing with this complexity using a set of long-developed tools and processes for practitioners and managers in organizations. For academics, future research investigating additional cases of knowledge-intensive organizations and business processes is expected to enhance the theory development process, the resulting framework, and its validity and generalizability. The core components of the KM infrastructure identified in this study are general and, therefore, may be relevant as a predominant KM structure of any knowledge-intensive organization, specifically of the support departments of such organizations. A logical and urgent continuation of this research would be to expand the KMIF by conducting more case studies within support divisions of high-tech organizations in the same industry segment as this study. Further research may also explore other knowledge-intensive divisions of high-tech organizations, such as R\&D, and examine how the KM framework may be adapted to these cases. Investigating how KM infrastructure frameworks are adopted over time in the context of KIBPs, how research is utilized in industry, and other relevant factors can help establish a link between academics and practitioners and, as a result, strengthen the impact of KM in the transformation of organizations to sustainability-oriented KM frameworks.

\section{Conclusions}

By combining formal and operational knowledge procedures into the operational work environment, this study aimed to increase our understanding of how KM infrastructure may improve KIBPs. Most organizations have vast amounts of organizational knowledge, but this knowledge is only valuable for the business if used to make better and faster decisions. Knowledge must be integrated into the workflow so as to spend less time looking for it and more time implementing it. KM projects have long become part of an organization's values and objectives. Most of the time, however, they are not incorporated into the operational work environment and remain disconnected from KIBP needs, staying more as specific tasks and practices related to traditional formal stand-alone KM.

Our study was sparked by our years of experience in the field of knowledge management. Consequently, we regard KM as a collection of socio-engineering tools and approaches that have still unfulfilled yet immense potential for facilitating KIBPs. Informed by evidence from the field, we developed a framework that integrates social and technical methods. KMIF acknowledges and encompasses the different types of KM procedures and tools-formal and operational knowledge procedures, operational and KM IS, culture, and training - in a way that allows the evaluation and improvement of an organization's KIBPs within a single frame of reference. The linkage between the operational and formal blocks is part of the KM facilitation procedures supporting an organization's attempt to fulfill its knowledge asset potential. Moreover, this structure defines operational knowledge, helping the organization make a dedicated effort based on context-dependent $\mathrm{KM}$ that is integrated into the operational work environment.

Author Contributions: Conceptualization, I.A.; I.H.; M.L.; methodology, I.A.; I.H.; software, I.A.; validation, I.A.; formal analysis, I.A.; M.L.; investigation, I.A.; resources, I.A.; I.H.; data curation, I.A., M.L.; writing—original draft preparation, I.A. writing—review and editing, I.H.; M.L.; visualization, I.A.; supervision, I.H.; M.L.; project administration, I.H. All authors have read and agreed to the published version of the manuscript. 
Funding: The APC was funded by CA Labs, CA Technologies.

Institutional Review Board Statement: The study was conducted according to the approval from the case study organization.

Informed Consent Statement: Informed consent was obtained from all subjects involved in the study.

Data Availability Statement: Not applicable.

Conflicts of Interest: The authors declare no conflict of interest.

\section{Appendix A. Interview Questions}

Hello. You have been nominated by your manager or director to be part of a discussion on knowledge management topics in Support. The goal of the Knowledge Management project is to improve knowledge availability for support engineers. I hope that the insights from our discussion will lead us to design and develop valuable knowledge management solutions for Support.

1. Name \& email, current organization, job category

2. How long have you been working in this job category?

3. What functions is your organization responsible for?

4. Give an outline of the most critical business processes you are involved in in Support. What is your role in these processes?

5. What is your role in these processes?

a. How would you describe your job to someone who is not part of [the organization]?

b. Give an organizational chart of the structure that relates to your position (departments, groups, units etc.). Where are your job activities in the process flow?

6. Is your work governed by standards? Which standards or scorecards?

Questions in the context of specific business processes—may be posed for each process described above

1. Which members are involved in the process as actors or stakeholders, including decision makers, providers, users, or beneficiaries of knowledge? (Please provide names and roles)

2. What digital/non-digital information resources do you use to perform your work tasks? (Information systems, file servers, ECM, DM, PC, paper boxes, people, groups)

3. Think of a person or group that you consider 'knowledgeable' and useful for carrying out your job. Please describe the role of each person and how they are involved in performing your tasks. What kind of information do they provide you?

Contact operator, senior support engineers, principal support engineers, sustaining engineering-Level 2, support center managers, support delivery managers, support availability managers, KM team, peer specialists, subject matter experts, quality team, web support team, R\&D

4. To what extent are these resources useful and to what extent do they help you carry out your job?

5. What are your expectations from electronic information resources?

6. Think of your own expertise and experience. Who are the consumers of your knowledge?

7. What activities do you undertake in order to perform your tasks?

8. What are the frequencies and durations of the processes/tasks? Describe the tasks' preconditions and post-conditions, their triggering events and decision-making points.

9. What risks are involved in carrying out your work?

10. When you cannot find information needed to carry out your job, where do you go to find it?

a. Would you contact colleagues from other [the organization] organizations for information on $(\mathrm{x})$ ? Think of a person, or group, or [the organization] sub-organizations that you consider 'knowledgeable' and useful for carrying 
out your job. Do you have an organizational map of knowledge experts in your job area?

b. What external factors/external organizations do you have to deal with in order to fulfill your job?

11. Think of your own expertise and experience. What do you do, or know, that if adopted by others in [the organization] would benefit their organization? What are your 'gems' that others don't always see?

12. Who are the organization's stakeholders and what is their interest in the business activities you carry out?

13. How are the processes actually executed in the organization, formally and informally? What styles of communication are common? What social and interpersonal skills are required? What kind of networking is desired?

14. What are the qualities and performance measures that the organization uses to determine whether tasks are executed successfully?

15. How do you keep yourself updated on issues related to [the organization] technical support?

16. Estimate how much time per week you spend searching for task-related information?

a. What proportion of the information you are looking for resides in electronic documents, papers or people (knowledge in the minds of people)

b. How do you find the information? What methods and tools do you use? (For example, searching a knowledge management system, searching email, specific websites and search engines)

17. What do you do with the information or documents you find?

18. Can you show me how you classify and organize information that is saved?

19. In general, how do you determine the correctness of the information you find? (Trust for information source, ranking ... )

Comments and Feedback

Do you have any ideas for improving the availability of information/knowledge required for your work? (Flow, collaboration environment, meta-data, etc.)

Do you have any questions for us, now that you've completed the interview and heard our questions for you?

For other interviews, are there any questions you think we should add, or changes you think would improve the interview from your side or from ours?

Closing

Key message 1: You've been great. Thanks so much for your insights from your experience. We truly appreciate the time you've taken to share your knowledge with us.

\section{Appendix B. Questionnaire}

You have been nominated as a key stakeholder, who is able to provide insights into the organizational technical support tools and processes. The purpose of this survey is to help the organization better understand and improve knowledge management throughout the technical support process.

Knowledge management is a set of systematic organizational processes and tools for acquiring, organizing, sustaining, applying, sharing, and maintaining tacit and explicit knowledge so as to enhance organizational and personal performance. The survey should take about 45 minutes to complete. Please answer each question carefully. If you can not complete the survey in a single session, simply complete the page you are on, and return to the survey at a later time from the same computer using the link in this email. You should be returned to your next survey question. In this survey the term 'Support Engineers' refers to 'Level 1 Support Engineers' unless otherwise noted.

(1) Please select your team name

(2) What format do you use to create issue-related information? You may choose multiple cells for each item 


\begin{tabular}{|c|c|c|c|c|c|c|c|c|}
\hline & Email & $\begin{array}{l}\text { Office: Excel, Word, } \\
\text { Power Point }\end{array}$ & PDF & SharePoint & $\begin{array}{c}\text { Star Trak } \\
\text { Mainframe }\end{array}$ & Star-Web & Jira & Paper \\
\hline \multicolumn{8}{|l|}{$\begin{array}{l}\text { Customer info (site id, } \\
\text { name, contacts, etc) }\end{array}$} & \\
\hline Issue info & & & & & & & & \\
\hline Problem info & & & & & & & & \\
\hline Product info & & & & & & & & \\
\hline Release info & & & & & & & & \\
\hline Solution info & & & & & & & & \\
\hline Training content & & & & & & & & \\
\hline
\end{tabular}

(3) Where do you store issue-related information? You may choose multiple cells for each item

\begin{tabular}{|c|c|c|c|c|c|c|c|c|}
\hline & Email & File Servers/Shares & $\begin{array}{c}\text { Personal } \\
\text { Computer }\end{array}$ & SharePoint & Mainframe & Star-Web & support.ca.com & Wiki \\
\hline $\begin{array}{c}\text { Customer info (site id, } \\
\text { name, contacts, etc) } \\
\text { Issue info } \\
\text { Problem info } \\
\text { Product info } \\
\text { Release info } \\
\text { Solution info } \\
\text { Training content }\end{array}$ & & & & & & & & \\
\hline
\end{tabular}

(4) Where do you look for relevant information when you are resolving an issue? You may choose multiple cells for each item

\begin{tabular}{|c|c|c|c|c|c|c|c|}
\hline & $\begin{array}{l}\text { Customer } \\
\text { Info }\end{array}$ & $\begin{array}{l}\text { Product } \\
\text { Info }\end{array}$ & $\begin{array}{l}\text { Issue Resolving } \\
\text { Info }\end{array}$ & $\begin{array}{c}\text { Similar Issues } \\
\text { Info }\end{array}$ & $\begin{array}{c}\text { Similar } \\
\text { Solution } \\
\text { Info }\end{array}$ & $\begin{array}{l}\text { Problem } \\
\text { Info }\end{array}$ & $\begin{array}{l}\text { New Release Info } \\
\text { (Fix, Updates, } \\
\text { New Version) }\end{array}$ \\
\hline $\begin{array}{c}\text { Best Practices of Services } \\
\text { Organization.com } \\
\text { Consumer knowledge base } \\
\text { Consult co-workers } \\
\text { Email } \\
\text { File Servers/Shares } \\
\text { Find.Organization.com } \\
\text { Green Books of SWAT } \\
\text { Issue Review System } \\
\text { Employee Portal-Enterprise } \\
\text { Accounts } \\
\text { Jira } \\
\text { Outside resources } \\
\text { Personal computer } \\
\text { CenterPoint (aka SharePoint) } \\
\text { Lists } \\
\text { StarTrak Mainframe } \\
\text { Star-Web } \\
\text { support.Organization.com } \\
\text { Training systems } \\
\text { Wiki }\end{array}$ & & & & & & & \\
\hline
\end{tabular}

(5) If you look for relevant information on file shares, please specify the file shares that you access/use:

(6) For each type of information system (on the left), please estimate its level of quality in terms of the following parameters: accuracy, recency, and ease of finding the information. If you are not familiar with a system, please indicate that in the last column. 
(7) For each type of knowledge item (on the left), please estimate its quality in terms of the following parameters: accuracy, recency, and ease of finding the information

\begin{tabular}{|c|c|c|c|c|c|c|c|c|c|c|c|c|c|c|c|}
\hline & \multicolumn{5}{|c|}{ Accuracy \& Trustworthiness } & \multicolumn{5}{|c|}{ Recency of Information } & \multicolumn{5}{|c|}{$\begin{array}{l}\text { Ease of Finding \& Retrieving } \\
\text { the Information }\end{array}$} \\
\hline & $\begin{array}{l}\text { Very } \\
\text { Bad }\end{array}$ & Bad & $\begin{array}{l}\text { Not } \\
\text { Sure }\end{array}$ & Good & $\begin{array}{l}\text { Very } \\
\text { Good }\end{array}$ & $\begin{array}{l}\text { Very } \\
\text { Bad }\end{array}$ & Bad & $\begin{array}{l}\text { Not } \\
\text { Sure }\end{array}$ & Good & $\begin{array}{l}\text { Very } \\
\text { Good }\end{array}$ & $\begin{array}{l}\text { Very } \\
\text { Bad }\end{array}$ & Bad & $\begin{array}{l}\text { Not } \\
\text { Sure }\end{array}$ & Good & $\begin{array}{l}\text { Very } \\
\text { Good }\end{array}$ \\
\hline $\begin{array}{l}\text { Customer info } \\
\text { Product info } \\
\text { Issue info } \\
\text { Solution info } \\
\text { Problem info } \\
\text { Training } \\
\text { content } \\
\text { Releases info }\end{array}$ & & & & & & & & & & & & & & & \\
\hline
\end{tabular}

(8) Where does the relevant knowledge exist for each type of information? Please choose the relative percentage for each source-each row should total 100\%)

\begin{tabular}{|c|c|c|c|c|c|c|c|c|c|c|c|c|c|c|c|c|c|c|c|c|c|c|c|c|c|c|c|}
\hline \multirow[b]{3}{*}{ Customer } & \multicolumn{9}{|c|}{$\begin{array}{c}\text { Public (Organizational Repositories) } \\
(\%)\end{array}$} & \multicolumn{9}{|c|}{$\begin{array}{c}\text { Non Public (Personal PC, Paper, Emails ... ) } \\
(\%)\end{array}$} & \multicolumn{9}{|c|}{$\begin{array}{l}\text { People's Mind } \\
(\%)\end{array}$} \\
\hline & 10 & 20 & 30 & 40 & 50 & 60 & 70 & 80 & 90 & 10 & 20 & 30 & 40 & 50 & 60 & 70 & 80 & 90 & 10 & 20 & 30 & 40 & 50 & 60 & 70 & 80 & 90 \\
\hline & & & & & & & & & & & & & & & & & & & & & & & & & & & \\
\hline Product & & & & & & & & & & & & & & & & & & & & & & & & & & & \\
\hline & & & & & & & & & & & & & & & & & & & & & & & & & & & \\
\hline Solution & & & & & & & & & & & & & & & & & & & & & & & & & & & \\
\hline info & & & & & & & & & & & & & & & & & & & & & & & & & & & \\
\hline $\begin{array}{c}\text { Problem } \\
\text { info }\end{array}$ & & & & & & & & & & & & & & & & & & & & & & & & & & & \\
\hline Training & & & & & & & & & & & & & & & & & & & & & & & & & & & \\
\hline Releases & & & & & & & & & & & & & & & & & & & & & & & & & & & \\
\hline & & & & & & & & & & & & & & & & & & & & & & & & & & & \\
\hline
\end{tabular}

(9) When you create an issue in Star, what is the best way to create keywords so that others may locate the issue easily?

- Authors create their own tags (keywords) for issues they create or modify

- Authors choose keywords from the organization's predefined list of values (if the required value is missing, it may be added)

- Keywords are generated automatically based on information inserted for the current issue

- $\quad$ Other (please specify)

(10) I prefer to use CenterPoint (aka SharePoint) knowledge portals because: please select all relevant statements

- It is interesting

- It is a central repository for all technical information

- It has a simple GUI that makes it usable

- I find the information useful and it provides me with shortcuts for completing my tasks

- My manager asked me to use it

- Other (please specify)

(11) I prefer not to use SharePoint knowledge portals because: please indicate all relevant statements

- I am too busy to use it

- It seems useless

- I do not understand how to use it

- The interface is not friendly

- The information in it seems unreliable

- The information is duplicated from other sources

- I prefer reading hard copy documents

- Other (please specify) 
(12) Are you comfortable with sharing your professional experience and innovative ideas within a sharable corporate-wide collaborative system (e.g. CenterPoint, aka SharePoint)? Please choose one suitable answer

- Yes, it allows me to answer each question only once

- Yes, it allows other people to see my answers

- Yes, it provides a single place for updates to a question, such as a searchable discussion forum

- No, because it takes a lot of time

- No, I prefer to help people by telephone

- No, I prefer to help people by email

- No, I prefer to help people in face-to-face meetings

- Other (please specify)

(13) Which of the following has potential to develop a successful knowledge management solution within your organization?

\begin{tabular}{|c|c|c|c|c|c|}
\hline & $\begin{array}{c}\text { No } \\
\text { Potential }\end{array}$ & $\begin{array}{c}\text { Slight } \\
\text { Potential }\end{array}$ & $\begin{array}{l}\text { Moderate } \\
\text { Potential } \\
\end{array}$ & $\begin{array}{c}\text { Good } \\
\text { Potential }\end{array}$ & $\begin{array}{l}\text { Excellent } \\
\text { Potential }\end{array}$ \\
\hline $\begin{array}{c}\text { Improve the information technology infrastructure } \\
\text { Develop systematic training for all support engineers } \\
\text { Develop an integrative organization repository of information } \\
\text { and knowledge } \\
\text { Develop effective and efficient methods of } \\
\text { gathering information } \\
\text { Encourage a culture that promotes sharing of knowledge } \\
\text { Provide incentives to support engineers who } \\
\text { contribute knowledge } \\
\text { Allow a place and time for support engineers to discuss their } \\
\text { personal knowledge } \\
\text { Allocate resources for generating knowledge } \\
\text { Encourage support engineers to be innovative and creative } \\
\text { Have well-defined keyword management }\end{array}$ & & & & & \\
\hline
\end{tabular}

(14) What are the main individual barriers to successful knowledge management in your organization?

(15) What are the main organizational barriers to successful knowledge management in your organization?

(16) What are the main technological barriers to successful knowledge management in your organization?

(17) How many hours per week do you spend creating knowledge documents as part of the "Write for success" program?

- More than $10 \mathrm{~h}$

- 7 to $10 \mathrm{~h}$

- 4 to $7 \mathrm{~h}$

- 1 to $4 \mathrm{~h}$

- Less than $1 \mathrm{~h}$ (but greater than 0)

- I do not participate in this program

(18) How important are each of the following CenterPoint (aka SharePoint) tools to your job:

\begin{tabular}{|c|c|c|c|c|}
\hline & Very Important & Moderately Important & Of Little Importance & Unimportant \\
\hline Announcements and alerts & & & & \\
\hline Calendar tools & & & & \\
\hline Discussion Board & & & & \\
\hline Document access and sharing & & & & \\
\hline Document creation and maintenance for the & & & & \\
\hline knowledge library & & & & \\
\hline Sharepoint Lists & & & & \\
\hline Surveys & & & & \\
\hline Links to other applications & & & & \\
\hline Other (please provide details in comment field below) & & & & \\
\hline
\end{tabular}

Additional comments:

(19) What improvements to the organizational tools, processes, and incentive programs would increase your contributions to knowledge creation, sharing, and maintenance? 


\begin{tabular}{|l|l|l|l|}
\hline 2054 & 0, & 94 \\
\hline
\end{tabular}

Thank you very much for your contribution.

\section{References}

1. Martins, V.W.; Rampasso, I.S.; Anholon, R.; Quelhas, O.L.; Leal Filho, W. Knowledge management in the context of sustainability: Literature review and opportunities for future research. J. Clean. Prod. 2019, 229, 489-500. [CrossRef]

2. Chiabrishvili, M.; Zaim, H. The role of knowledge management for long-term sustainability in Kuwait companies. Middle East J. Manag. 2018, 4, 340-355. [CrossRef]

3. Demir, A.; Budur, T.; Omer, H.M.; Heshmati, A. Links between knowledge management and organisational sustainability: Does the ISO 9001 certification have an effect? Knowl. Manag. Res. Pract. 2021, 20, 1-4. [CrossRef]

4. López-Torres, G.C.; Garza-Reyes, J.A.; Maldonado-Guzmán, G.; Kumar, V.; Rocha-Lona, L.; Cherrafi, A. Knowledge management for sustainability in operations. Prod. Plan. Control 2019, 30, 12-26. [CrossRef]

5. Eccles, R.; Ioannou, I.; Serafeim, G. The Impact of Corporate Sustainability on Organizational Processes and Performance. Manag. Sci. 2014, 60, 2835-2857. [CrossRef]

6. Ioannis, I.; Serafeim, G. Corporate Sustainability: A Strategy? HBS Working Paper No. 19-065; HBS: Boston, MA, USA, 2019. Available online: https:/ / www.hbs.edu/faculty/Publication\%20Files/19-065_16deb9d6-4461-4d2f-8bbe-2c74b5beffb8.pdf (accessed on 10 January 2020).

7. Wojtkowiak, D.; Cyplik, P. Operational Excellence within Sustainable Development Concept-Systematic Literature Review. Sustainability 2020, 12, 7933. [CrossRef]

8. Di Vaio, A.; Varriale, L. Digitalization in the Sea-Land Supply Chain: Experiences from Italy in Rethinking the Port Operations within Inter-Organizational Relationships. Prod. Plan. Control. 2020, 31, 220-232. [CrossRef]

9. Georgise, F.B.; Wuest, T.; Thoben, K.-D. SCOR Model Application in Developing Countries: Challenges \& Requirements. Prod. Plan. Control 2017, 28, 17-32.

10. Kerpedzhiev, G.D.; König, U.M.; Röglinger, M.; Rosemann, M. An Exploration into Future Business Process Management Capabilities in View of Digitalization. Bus. Inf. Syst. Eng. 2021, 63, 83-96. [CrossRef]

11. Centobelli, P.; Cerchione, R.; Esposito, E. Knowledge Management in Startups: Systematic Literature Review and Future Research Agenda. Sustainability 2017, 9, 361. [CrossRef]

12. Sallos, M.P.; Yoruk, E.; Garcia-Perez, A. A business process improvement framework for knowledge-intensive entrepreneurial ventures. J. Technol. Transf. 2016, 42, 354-373. [CrossRef]

13. Bitkowska, A. The relationship between Business Process Management and Knowledge Management-Selected aspects from a study of companies in Poland. J. Entrep. Manag. Innov. 2020, 16, 169-193. [CrossRef]

14. Cerchione, R.; Esposito, E. Using knowledge management systems: A taxonomy of SME strategies. Int. J. Inf. Manag. 2017, 37, 1551-1562. [CrossRef]

15. Sobolewska, O. Knowledge-oriented business process management as a catalyst to the existence of network organizations. J. Entrep. Manag. Innov. 2020, 16, 107-131. [CrossRef]

16. Chung, T.A.; Tseng, C.Y. The knowledge intensity and the economic performance in Taiwan's knowledge intensity business services. Econ. Res. 2019, 32, 797-811. [CrossRef]

17. Massingham, P.; Al Holaibi, M. Embedding Knowledge Management into Business Processes. Know. Process. Mgmt. 2017, 24, 53-71. [CrossRef]

18. Abuezhayeh, S.W.; Ruddock, L.; Shehabat, I. Integration between knowledge management and business process management and its impact on the decision making process in the construction sector: A case study of Jordan. Constr. Innov. 2021. [CrossRef]

19. Gamble, J.R. Tacit vs explicit knowledge as antecedents for organizational change. J. Organ. Chang. Manag. 2020, 33, 1123-1141. [CrossRef]

20. Castaneda, D.I.; Toulson, P. Is it possible to share tacit knowledge using information and communication technology tools? Glob. Knowl. Mem. Commun. 2021. [CrossRef]

21. Hlatshwayo, M. Information and knowledge management. J. Inf. Knowl. Manag. 2019, 1-12.

22. Davenport, T.H. Process Management for Knowledge Work. In Handbook on Business Process Management. International Handbooks on Information Systems; Vom Brocke, J., Pernici, B., Eds.; Springer: Berlin/Heidelberg, Germany, 2015. [CrossRef]

23. van den Berg, H.A. Three shapes of organizational knowledge. J. Knowl. Manag. 2013, 17, 159-174. [CrossRef]

24. Wong, A. Power Perspective to Interunit Knowledge Transfer: Linking Knowledge Attributes to Unit Power and the Transfer of Knowledge. J. Manag. 2008, 34, 127-150. [CrossRef]

25. Liebowit, J. Addressing the Human Capital Crisis in the Federal Government: A Knowledge Management Perspective; ButterworthNeinemann: Oxford, UK, 2004.

26. Lehaney, B.; Clarke, S.; Coakes, E.; Jack, G. Beyond Knowledge Management; Idea Group Publishing: Hershey, PA, USA, 2004.

27. Brajer-Marczak, R. Elements of knowledge management in the improvement of business processes. Management 2016, $20,242-260$. [CrossRef] 
28. Gronau, N.; Weber, E. Management of Knowledge Intensive Business Processes. In Business Process. Management; Desel, J., Pernici, B., Weske, M., Eds.; Springer: Berlin/Heidelberg, Germany, 2005.

29. Vasilecas, O.; Kalibatiene, D.; Lavbič, D. Rule-and context-based dynamic business process modelling and simulation. J. Syst. Softw. 2016, 122, 1-15. [CrossRef]

30. Pang, S.; Li, Y.; He, H.; Lin, C. A model for dynamic business processes and process changes. Chin. J. Electron. 2011, 20, $632-636$.

31. Kalibatiene, D.; Vasilecas, O. A survey on modeling dynamic business processes. Peerj Comput. Sci. 2021, 7, 2-7. [CrossRef]

32. Eshuis, R. Feature-oriented composition of declarative artifact-centric process models. In Business Process. Management; Weske, M., Montali, M., Weber, I., vom Brocke, J., Eds.; Springer: Berlin/Heidelberg, Germany, 2018. [CrossRef]

33. Drucker, P.F. The Age of Social Transformation. Atl. Mon. 1994, 274, 53-80.

34. Lee, W.B.; Shek, V.; Cheung, B. Auditing and Mapping the Knowledge Assets of Business Processes-An Empirical Study. In Knowledge Science, Engineering and Management. KSEM 2007; Lecture Notes in Computer Science; Zhang, Z., Siekmann, J., Eds.; Springer: Berlin/Heidelberg, Germany, 2007. [CrossRef]

35. Forstenlechner, I.; Lettice, F. Cultural differences in motivating global knowledge workers. Equal. Oppor. Int. J. 2007, 26, 823-833. [CrossRef]

36. Andriushchenko, K.; Pokotylska, N.; Ortina, G.; Zborovska, O.; Budnyak, L. Digital Transformation of Business Processes of an Enterprise. TEM J. 2020, 9, 1800-1808. [CrossRef]

37. Ahmad, T.; Van Looy, A. Business Process Management and Digital Innovations: A Systematic Literature Review. Sustainability 2020, 12, 6827. [CrossRef]

38. Alvarenga, A.; Matos, F.; Godina, R.; Matias, J.C.O. Digital Transformation and Knowledge Management in the Public Sector. Sustainability 2020, 12, 5824. [CrossRef]

39. Abualooush, S.; Masa'deh, R.; Bataineh, K.; Alrowwad, A. The Role of Knowledge Management Process and Intellectual Capital as Intermediary Variables between Knowledge Management Infrastructure and Organization Performance. Interdiscip. J. Inf. 2018, 13, 279-309. [CrossRef]

40. Lustri, D.; Miura, I.; Takahashi, S. Knowledge management model: Practical application for competency development. Learn. Organ. J. 2007, 14, 186-202. [CrossRef]

41. Karasti, H.; Blomberg, J. Studying Infrastructure Ethnographically. CSCW 2018, 27, 233-265. [CrossRef]

42. Kushwaha, P.; Rao, M.K. Integrative Role of KM Infrastructure and KM Strategy to Enhance Individual Competence: Conceptualizing Knowledge Process Enablement. Commun. Netw. 2015, 8, 376-396. [CrossRef]

43. Lai, L.F. A knowledge engineering approach to knowledge management. Inf. Sci. 2007, 177, 4072-4094. [CrossRef]

44. Jewels, T.J.; Marilyn, F. Factors Influencing Knowledge Sharing in Information Technology Projects. E Serv. J. 2006, 5, 99-117. [CrossRef]

45. Liophanich, C. An Investigation of Knowledge Management Implementation: Multiple Case Study in Mobile Telecommunication Industry. J. Ind. Intell. Inf. 2014, 2, 159-163. [CrossRef]

46. Toro, U.; Milind, J. A Review of Literature on Knowledge Management using ICT in Higher Education. Comput. Technol. Appl. 2014, 4, 62-67.

47. Sensuse, D.I.; Lestari, P.I.; Hakim, S.A. Exploring Factors Influencing Knowledge Sharing Mechanisms and Technology to Support the Collaboration Ecosystem A Review. DESIDOC J. Libr. Inf. Technol. 2021, 41, 226-234. [CrossRef]

48. Linderman, K.; Schroeder, R.G.; Sanders, J. A knowledge framework underlying process management. Decis. Sci. 2010, 41, 689-719. [CrossRef]

49. Martínez-Martínez, A.; Suárez, L.M.C.; Montero, R.S.; del Arco, E.A. Knowledge management as a tool for improving business processes: An action research approach. J. Ind. Eng. Manag. 2018, 11, 276-289. [CrossRef]

50. Paschek, D.; Ivascu, L.; Draghici, A. Knowledge Management-The Foundation for a Successful Business Process Management. Procedia Soc. Behav. Sci. 2018, 238, 182-191. [CrossRef]

51. Yin, R.K. Case study research, design and methods, 3rd ed.; Sage Publications: Newbury Park, CA, USA, 2003.

52. Strauss, A.L.; Corbin, J. Basics of Qualitative Research: Techniques and Procedures for Developing Grounded Theory; Sage Publications: Thousand Oaks, CA, USA, 1998.

53. Bell, J. Doing Your Research Project; Open University Press: Berkshire, UK, 2005.

54. Glaser, B.G. Conceptualization: On Theory and Theorizing Using Grounded Theory. Int. J. Qual. Methods 2002, 1, 1-31. [CrossRef]

55. Robson, C. Real world research: A Resource for Social Scientists and Practitioner-Researchers; Blackwell Publishers Ltd.: Hoboken, NJ, USA, 2002.

56. Pandit, N.R. The creation of theory: A recent application of the grounded theory method. Qual. Rep. 1996, 2, 1-14. [CrossRef]

57. Levy, M.; Hadar, I.; Aviv, I. A requirements engineering methodology for knowledge management solutions: Integrating technical and social aspects. Requir. Eng. 2018, 24, 503-521. [CrossRef]

58. Goswami, M.; Goswami, A. Integrated Framework for Implementing Knowledge Management in Contemporary Organizations. Glob. J. Manag. Bus. Stud. 2013, 3, 611-618.

59. Johannsen, F.; Fill, H. Codification of Knowledge in Business Process Improvement Projects. In Proceedings of the 22nd European Conference on Information Systems ECIS14, Tel Aviv, Israel, 9-11 June 2014.

60. Guba, E.G. Criteria for assessing the trustworthiness of naturalistic inquiries. ECTJ 1981, 29, 75-91. [CrossRef]

61. Maxwell, J.A. Qualitative Research Design: An Interactive Approach, 3rd ed.; Sage Publications: Thousand Oaks, CA, USA, 2013. 
62. Candela, A.G. Exploring the function of member checking. Qual. Rep. 2019, 24, 619-628. [CrossRef]

63. Birt, L.; Scott, S.; Cavers, D.; Campbell, C.; Walter, F. Member checking: A tool to enhance trustworthiness or merely a nod to validation? Qual. Health Res. 2016, 26, 1802-1811. [CrossRef] 